\title{
Do Bond Investors Price Tail Risk Exposures of
}

\section{Financial Institutions?}

\author{
Sudheer Chava* $^{*} \quad$ Rohan Ganduri ${ }^{\dagger} \quad$ Vijay Yerramilli ${ }^{\ddagger}$
}

March 2014

\begin{abstract}
We analyze whether bond investors price tail risk exposures of financial institutions using a comprehensive sample of bond issuances by U.S. financial institutions. Although primary bond yield spreads increase with an institutions' own tail risk (expected shortfall), systematic tail risk (marginal expected shortfall) of the institution doesn't affect its yields. The relationship between yield spreads and tail risk is significantly weaker for depository institutions, large institutions, government-sponsored entities, politicallyconnected institutions, and in periods following large-scale bailouts of financial institutions. Overall, our results suggest that implicit bailout guarantees of financial institutions can exacerbate moral hazard in bond markets and weaken market discipline.
\end{abstract}

*Scheller College of Business, Georgia Institute of Technology; 800 W. Peachtree St NW, Atlanta, GA 30309; email: sudheer. chava@scheller.gatech.edu.

†Scheller College of Business, Georgia Institute of Technology; 800 W. Peachtree St NW, Atlanta, GA 30309; email: rohan.ganduri@scheller.gatech.edu.

${ }^{\ddagger}$ C. T. Bauer College of Business, University of Houston; 240D Melcher Hall, University of Houston, Houston, TX 77204; email: vyerramilli@bauer.uh.edu. We are grateful to the 2013 GARP Risk Management Program for financial support. We would like to thank Viral Acharya, Andy Winton, and seminar participants at Scheller College of Business, Georgia Tech for helpful comments and suggestions. 


\section{Introduction}

The experience of the recent financial crisis highlights two aspects of risk-taking by financial institutions that reinforced each other in the run-up to the crisis and contributed to an increase in systemic risk. ${ }^{1}$ First, executives at financial institutions have incentives to take on tail risks, that is, risks that generate severe adverse consequences with small probability but, in return, offer generous returns the rest of the time (Rajan (2005), Kashyap, Rajan, and Stein (2008), Hoenig (2008) and Strahan (2013)). Second, institutions have incentives to herd with other institutions in investment choices, thus increasing their exposure to systemically important sectors, such as housing, because they expect to be bailed out in the event of a systemic crisis (Farhi and Tirole (2011)).

Given the importance of the financial sector and the negative externality on the real economy from a widespread failure of financial institutions, there is an increased focus on how to contain tail risk exposures of financial institutions. One recurring idea in financialsector regulation is that regulators increase their reliance on "market discipline" in controlling institutions' risk exposures. However, market discipline can only be effective if investors price the risk exposure of financial institutions. In this paper, we examine whether bond market investors price the tail risk exposure of financial institutions in which they invest.

Financial institutions are highly-levered entities and their equity capital may not be adequate to absorb the large losses that materialize when a tail event occurs. Given that bondholders hold uninsured liabilities that do not share in the upside from tail risk but may have to absorb losses when the tail risk materializes, it is rational to expect that they will demand higher yield spreads from institutions with higher tail risk exposures. This should be particularly true for investors in subordinated bonds, whose claims are junior to those of senior bondholders. $^{2}$ On the other hand, there are two reasons why bondholders may not price tail

\footnotetext{
${ }^{1}$ Systemic risk is the risk of widespread failure of financial institutions or the freezing up of capital markets (see Acharya, Pedersen, Philippon, and Richardson (2010) and Hansen (2011) for a more detailed discussion).

${ }^{2}$ In fact, Pillar III of the New Basel Capital Accord places special emphasis on market discipline through subordinated bonds, which are meant to act as loss-absorbing instruments.
} 
risk exposures. Bondholders of systemically important financial institutions (SIFIs) may rationally anticipate a taxpayer-funded bailout of their institution in the event of a systemic crisis, and thus, may not price the institution's exposure to tail risk, especially systematic tail risk. Alternatively, it may be that investors neglect low-probability nonsalient risks and are caught unaware when the debt they had considered safe turns out to be risky (Bordalo, Gennaioli, and Shleifer (2012) and Gennaioli, Shleifer, and Vishny (2012)). ${ }^{3}$

We test these hypotheses using a large sample of primary bond issuances by U.S. financial institutions during the 1990 to 2010 period. We focus on the primary bond market because it directly affects the cost of institutions' debt capital. We measure an institution's own tail risk using expected shortfall $(E S)$, which measures its expected loss conditional on returns being less than some $\alpha$-quintile. Specifically, ES is defined as the negative of the average return on the institution's stock over the $5 \%$ worst return days for the institution over the year; i.e., $E S$ measures the institution's loss in its own left tail. We capture the tail dependence between the institution and the stock market using the marginal expected shortfall $(M E S)$, which measures the institution's expected loss when the stock market is in its left tail (see Acharya, Pedersen, Philippon, and Richardson (2010)). Specifically, MES is defined as the negative of the average return on the institution's stock over the $5 \%$ worst return days for the S\&P 500 index over the year. ${ }^{4}$ Henceforth, we will refer to MES as the institution's systematic tail risk, to distinguish it from $E S$, which may also be driven by risk factors that are idiosyncratic to the institution.

We first examine whether the yield spreads on new bond offerings at issuance (Yield Spread) vary with the tail risk exposure of the financial institution issuing the bonds. As expected, we find a robust positive relationship between Yield Spread and ES, which indicates that the cost of debt capital is higher for institutions with a higher total tail risk. Interestingly,

\footnotetext{
${ }^{3}$ This view is supported by Jarrow, Li, Mesler, and van Deventer (2007) and Coval, Jurek, and Stafford (2009) who show that the sensitivities of structured products like CDOs to home prices were not taken into account by rating agencies and investors alike.

${ }^{4}$ Acharya, Pedersen, Philippon, and Richardson (2010) show that MES is an important determinant of a financial institution's overall contribution to systemic risk, and that institutions with high $M E S$ before the onset of the financial crisis had worse stock returns during the crisis years, all else equal.
} 
however, we fail to detect any significant relationship between Yield Spread and MES; that is, bond market investors seem to ignore an institution's systematic tail risk. To alleviate the concern that the effect of tail risk may be subsumed by a bond's credit rating or an institution's size and leverage, we estimate our regression after omitting these important controls, and obtain qualitatively similar results. To test the robustness of this result, we also regress Yield Spread against other well-known risk measures, and arrive at a similar conclusion: Yield Spread increases with the institution's idiosyncratic risk (e.g., standard deviation of the institution's abnormal stock return) but does not vary with the institution's systematic risk (e.g., Beta).

We next explore how the relationship between yield spreads and tail risk varies with different bond characteristics that can affect an institution's default risk and the loss given default. When we distinguish between senior and subordinate bonds, we find that, as expected, the positive relationship between yield spreads and $E S$ is significantly stronger for subordinated bonds. However, the pricing of systematic tail risk MES does not vary between senior and subordinated bonds. In fact, a more striking result is that the institutions' $M E S$ is not priced even in the case of subordinated bonds. We also find that, as expected, the positive relationship between yield spreads and tail risk is stronger for bonds with poorer credit ratings.

Next, we examine how the pricing of tail risk varies with firm characteristics that may affect bailout expectations. As Strahan (2013) highlights, if investors place a positive probability that creditors would be protected in the event of failure, the prices of financial instruments would be distorted - the greater the probability, the greater the distortion. Consistent with the existence of too-big-to-fail (TBTF) subsidies for large financial institutions (e.g., see Acharya et al. (2013)), we find that the relationship between yield spreads and total tail risk ES is weaker for large financial institutions. However, there is no such variation in terms of the pricing of $M E S$, which is not priced regardless of the institution's size. An interesting class of institutions in our sample are the government-sponsored entities (GSEs) such as Fannie Mae and Freddie Mac. Although bonds issued by GSEs carry no explicit government guarantee of 
creditworthiness, there is a perception of an implicit guarantee because it is widely believed that the government will not allow such important institutions to fail or default on their debt (Strahan (2013)). Consistent with the existence of such an implicit guarantee, we find that the relationship between yield spreads and tail risk measures is significantly weaker for GSEs.

We conduct several additional tests to further distinguish between the moral-hazard hypothesis and the nonsalient-risks hypothesis. First, we estimate our regressions separately for the following four categories of institutions: depository institutions, broker-dealers, insurance companies, and other financial institutions. Institutions across these categories vary not only in terms of their risk exposures and balance-sheet composition, but also in terms of implicit bailout guarantees from the government. For instance, ever since the bailout of the Continental Illinois National Bank in 1984, the FDIC and other regulatory agencies have repeatedly indicated that they consider large banks too-big-to-fail (TBTF) because their closure might destabilize the financial system and impose a negative externality on the real economy. On the other hand, there are no implicit guarantees for debt issued by insurance companies as these are less likely to be considered systemically important. Thus, as per the moral-hazard hypothesis, the relationship between bond yield spreads and tail risk should be weaker for depository institutions compared with other types of financial institutions.

Consistent with this argument, we uncover striking differences in the pricing of tail risk between depository institutions and other types of financial institutions. We find that neither the total tail risk $E S$ nor the systematic tail risk $M E S$ is priced in the case of bonds issued by depository institutions, whereas both $E S$ and $M E S$ are priced in the case of bonds issued by broker-dealers and insurance companies. More strikingly, we find that $E S$ and $M E S$ are not priced even in the case of subordinated bonds issued by depository institutions. These results cast serious doubt on the idea that market discipline can be used to control the tail risk exposure of depository institutions.

Second, we examine how the relationship between yield spreads and tail risk varies based on the political connectedness of financial institutions. The idea is to exploit political con- 
nectedness as a source of cross-sectional variation in bailout expectations, because politically connected institutions are more likely to receive government bailouts (Faccio et al. (2006)). To test this idea, we hand-collect information on corporate lobbying expenditures by financial institutions from the Center for Responsive Politics (CRP). Consistent with the moral-hazard hypothesis, we find that the relationship between yield spreads and tail risk is significantly weaker for politically-connected institutions compared with non-connected institutions.

Third, we examine how the relationship between yield spreads and tail risk varies in the immediate aftermath of crisis events, such as the Long Term Capital Management (LTCM) crisis and the recent financial crisis. The idea underlying this test is to exploit the time-series variation in bailout expectations following the large-scale bailouts of troubled institutions during these crises. Not surprisingly, we find an across-the-board increase in the cost of debt for all financial institutions following a crisis event. However, consistent with the moral-hazard hypothesis, the relationship between yield spreads and tail risk is significantly weaker in the immediate aftermath of the LTCM crisis and the recent financial crisis. In sharp contrast, we do not find any such patterns surrounding the dotcom crisis of 2001. This is interesting because the dotcom crisis was confined to the technology sector and did not lead to bailouts of financial institutions. This differential impact of the dotcom crash compared with the other two crisis events suggests that our results are more likely driven by expectations of future bailouts rather than a general neglect of nonsalient risks.

Our paper is closely related to and complements the results in a recent paper by Acharya et al. (2013) that finds that secondary bond yield spreads of large financial institutions are lower compared with other financial institutions even after controlling for their risk exposures. They attribute this phenomenon to investor expectations of implicit state guarantees for large institutions. Our paper differs from theirs in the following respects: First, we focus on primary bond yield spreads that directly reflect the institutions' cost of debt capital. Second, our analysis is focused on the pricing of tail risk measures that are of particular concern to bondholders, especially investors in subordinated bonds. Finally, we provide further support 
for the moral-hazard hypothesis by showing that the pricing of tail risk is significantly weaker for politically connected institutions compared with non-connected institutions. Overall, our evidence points to moral hazard in the primary debt markets for financial institutions and complements the secondary debt market evidence in Acharya et al. (2013).

Our paper is related to prior studies of bank market discipline that focus on whether uninsured bank liabilities such as certificates of deposit (CDs) and subordinated notes and debentures (SNDs) contain appropriate risk premia. The literature generally concludes that CD rates paid by large money-center banks include significant default risk premia (e.g., see Ellis and Flannery (1992), Hannan and Hanweck (1988), and Cargill (1989)). On the other hand, the literature is divided with respect to the pricing of SNDs. Using a sample from 1983 and 1984, Avery, Belton, and Goldberg (1988) and Gorton and Santomero (1990) fail to detect any relationship between SND pricing and balance sheet measures of bank risk. However, examining a longer sample period, Flannery and Sorescu (1996) conclude that SND prices become more sensitive to risk measurements as expectations of government-sponsored bailouts decrease. The main difference between our study and this literature is that we focus exclusively on the pricing of tail risk exposures of financial institutions. Similar to Avery, Belton, and Goldberg (1988) and Gorton and Santomero (1990), we fail to find any evidence that subordinated bondholders of depository institutions care more about tail risk than senior bondholders. Also, similar to Flannery and Sorescu (1996), we find that the pricing of tail risk changes with expectations of government bailouts.

Past research has highlighted the perverse impact of implicit bailout guarantees on risktaking behavior of financial institutions. This literature argues that expectations of future systemic bailouts causes banks to correlate their risk exposure and take on high leverage (Farhi and Tirole (2011)), incentivizes small banks to herd together with large banks and increases the risk that many banks fail together (Acharya and Yorulmazer (2007)), and generally exacerbates the moral hazard of banks and bank managers (Bernardo, Talley, and Welch (2011) and Ratnovski and DellAriccia (2012)). We contribute to this literature by highlight- 
ing how implicit bailout guarantees also exacerbate the moral hazard of bond investors, thus undermining bank market discipline. Our finding is also in line with a recent study by Kelly, Lustig, and Van Nieuwerburgh (2011) that shows that a large amount of aggregate tail risk is missing from the price of financial sector crash insurance (i.e., price of puts on the financial sector index) during the recent financial crisis, which suggests that investors in the options market are pricing in a collective government guarantee for the financial sector.

Our study has potential regulatory implications in favor of internal restructuring/bail-in provisions, which lower the expectations of future government bailouts. In particular, it is important that bondholders are made to share in any loss arising from the institution's failure. This is essential in restoring market discipline and ensuring that prices of uninsured liabilities of financial institutions are in line with their risk exposures. Possibly recognizing these issues, Mario Draghi, President of the European Central Bank (ECB), recently advocated that even senior bondholders must share in the losses at the worst-hit savings banks in Spain. This was in sharp contrast to the bailout of Irish banks in late 2010 in which unsecured senior bondholders were paid in full using taxpayer money even though they had absolutely no form of government guarantee.

The remainder of the paper is organized as follows. We describe our data sources and construction of variables in Section 2, and provide descriptive statistics and preliminary results

in Section 3. We present our main empirical results in Section 4. We do additional tests in Section 5 to distinguish between our competing hypotheses. Section 6 concludes the paper.

\section{Data, Sample Construction, and Key Variables}

Given the focus of our paper, our sample comprises only bonds issued by U.S. financial institutions over the 1990 to 2010 period. Following Acharya et al. (2010), we classify U.S. financial institutions into the following four groups based on SIC codes: depositories, which have a 2-digit SIC code of 60 (e.g., Bank of America, JP Morgan, Citigroup, etc.); broker-dealers, 
which have a 4-digit SIC code of 6211 (e.g., Goldman Sachs, Morgan Stanley, etc.); insurance companies, which have a 2-digit SIC code of either 63 or 64 (e.g., AIG, Metlife, Prudential, etc.); and other financial institutions, which have a 2-digit SIC code of 61, 62, 65 or 67, and consist of nonbank finance companies (e.g., American Express), real estate companies (e.g., CIT Group), and GSEs (e.g., FNMA and FHLM), etc. We include all financial institutions in our sample regardless of their size. We have verified that our results are qualitatively similar even if we confine our analysis to large institutions, defined as those with market capitalization in excess of $\$ 5$ billion dollars over the entire sample period. The names of these large U.S. financial institutions are listed in Appendix A.

We obtain primary bond market data from Mergent's Fixed Investment Securities Database (FISD). FISD is a comprehensive database that provides issue details for over 140,000 corporations, U.S. agencies, and U.S. Treasury debt securities. ${ }^{5}$ We restrict our sample to U.S. domestic bonds and exclude yankee bonds, bonds issued via private placements, and issues that are asset-backed or have credit-enhancement features. We also exclude preferred stocks, mortgage-backed securities, trust-preferred capital, and convertible bonds. ${ }^{6}$ We include only ratings issued by the top three NRSROs - Standard and Poor (S\&P), Moody's, and Fitch. Our sample consists of both senior and subordinated bonds. ${ }^{7}$ We obtain firm-level control variables from COMPUSTAT's quarterly firm fundamentals file and merge this information with the primary market data.

Our main dependent variable of interest is Yield Spread, which is the yield to maturity (YTM) on the bond at issuance minus the YTM on a Treasury security with comparable maturity. Another variable of interest is Rating, which measures the bond's credit rating at

\footnotetext{
${ }^{5}$ FISD contains detailed information for each issue such as the issuer name, bond yields, bond yield spreads over the closest benchmark treasury, maturity date, offering amount, bond types, optionality features, rating date, rating level, and the agency that rated the issue, etc. See Chava et al. (2010) for more details of the FISD database.

${ }^{6}$ Lehman Brothers and Morgan Stanley issued large number of equity-linked bonds in 2007 and 2008. Such issues were dropped after a search based on the issue description field.

${ }^{7}$ FISD usually provides information regarding the seniority of the bond issue. In cases where the information is not provided, we obtain the missing seniority information by matching the issue in FISD using its complete CUSIP with the corresponding issue in Moody's Default Risk Database (DRS) and S\&P's CUSIP master file. Additionally, we also classify issues as senior or subordinated based on the issue description for bonds.
} 
issuance. To obtain Rating, we first convert the credit ratings provided by S\&P (Moody's) into an ordinal scale starting with 1 as AAA (Aaa), 2 as AA+ (Aa1), 3 as AA (Aa2), and so on until 22, which denotes the default category. As Fitch provides three ratings for default, we follow the existing literature and chose 23 instead of 22 for the default category, which is the average of the three default ratings; i.e., DD. Because each bond issue may be rated by multiple agencies, we compute Rating as the simple average of the ordinal rating assigned by each rating agency. Note that by construction, a lower value for Rating denotes a better credit quality at issuance.

We obtain stock price data from CRSP and use it to compute our risk measures. We measure tail risk using expected shortfall $(E S)$, which is widely used within financial firms to measure expected loss conditional on returns being less than some $\alpha$-quintile. Its computation involves identifying the $5 \%$ worst return days during the year for the firm's stock (i.e., days on which the return was lower than its fifth-percentile cutoff), and then computing the negative of the average of the firm's daily returns on these days. We measure systematic tail risk using marginal expected shortfall $(M E S)$, which measures the firm's expected loss when the market is in its left tail (see Acharya et al. (2010)). Specifically, MES is defined as the negative of the average return on the firm's stock over the 5\% worst return days for the S\&P500 index over the year. As we show below, there is a high correlation between $E S$ and $M E S$ in our sample, which is not surprising: given the systemic importance of the financial sector, financial institutions are more likely to experience a tail event when the market as a whole experiences a tail event.

Apart from the tail risk measures, we also compute two commonly used measures of risk: Aggregate Risk, which is a measure of the total firm-specific risk and defined as the standard deviation of the firm's daily excess return (i.e., daily return on a firm's stock in excess of the daily return on the S\&P500 index) over the year; and Beta, which is a measure of systematic risk, and is obtained by estimating the market model $R_{i t}=\alpha_{i}+\beta_{i} R_{m t}+\epsilon_{i t}$ using daily returns over the year. We use a rolling yearly window to compute the risk measures, so that 
for each quarter, risk measures are computed using the information from the preceding four quarters. For example, the risk measures pertaining to quarter from April 2007 to June 2007 are computed using the stock and S\&P returns over the one-year period from April 2006 to March 2007.

\section{$3 \quad$ Descriptive Statistics and Preliminary Results}

\subsection{Summary Statistics}

We provide a year-wise summary of bond offerings by financial institutions during the 1990 to 2010 period in Table I. As can be seen, there is a great deal of variation in total annual bond issuances by number over our sample period, with the 1992-1995 period being the most active in terms of number of bonds issued. However, although there were fewer issues in the latter half of the sample period, the median offering amount in the second half of the sample period is significantly higher than in the first half. Therefore, examining the total dollar amount issued each year, we find that the later half of the sample period has a larger dollar amount of bonds issued even though there are a fewer number of total issues in this period. The majority of the sample consists of senior bonds, with subordinated bonds making up only $18 \%$ of total issuances by number. A little more than half of the bonds in our sample have a maturity of less than 10 years and about half have a redeemable feature.

We provide the mean and median values (in parentheses) of the key variables by institution type in Panel B of Table I. Examining firm characteristics, we see that broker-dealers have the highest leverage, whereas insurance companies have the lowest leverage. On average, depository and broker-dealer institutions are also larger (higher $\log ($ assets)) and better rated (lower Rating) than insurance firms. Consistent with Acharya et al. (2010), depository institutions have lower aggregate risk and lower tail risk (both $E S$ and $M E S$ ), whereas brokerdealers have the highest level of systematic risk (Beta), tail risk $(E S)$, and systematic tail risk $(M E S)$ mainly due to the nature of their business. Other financial institutions account for 
half of the total bond issuances in our sample; out of these, GSEs account for about $40 \%$. Depository institutions account for about a quarter of the total bond issuances by number, whereas broker-dealers and insurance firms together account for another quarter. However, as can be seen from the mean and median offering sizes, the bond offerings by broker-dealers and depository institutions are much larger in size compared with those of insurance companies and other financial institutions. Depository institutions are the main issuers of subordinated debt, which accounts for around $40 \%$ of their bond offerings. This is mainly due to regulatory reasons. As per the Basel Capital Accord, subordinated debt is among the three types of eligible loss-absorbing instruments that banks are required to issue at regular intervals in order to facilitate market discipline.

\subsection{Correlations}

We provide univariate correlations between our key variables in Table II. Not surprisingly, total tail risk $(E S)$ and systematic tail risk $(M E S)$ are highly correlated. This suggests that, given the systemic importance of the financial sector, financial institutions are more likely to experience a tail event when the market as a whole experiences a tail event. Therefore, in our subsequent multivariate analysis, we are careful to only include either ES or MES as an independent variable. We also note the high correlation between ES and Aggregate Risk, which suggests that riskier institutions also have higher tail risk. Similarly, the high correlation between Beta and MES suggests that institutions with high overall systematic risk also have higher systematic tail risk.

We find that Yield Spread is positively correlated with the tail risk measures (ES, MES)

and Aggregate Risk. We must, however, interpret this with caution because these are univariate correlations that do not control for other important institutional characteristics. In particular, Yield Spread is negatively correlated with Size and Leverage, which are two important characteristics that are positively correlated with tail risk. In the case of rating assignments, we find that Rating is positively correlated with ES and Aggregate Risk, suggesting that in- 
stitutions with higher tail risk and higher total risk are assigned worse ratings. On the other hand, Rating is uncorrelated with MES. As with the yield spreads, we find that Rating is highly negatively correlated with Size and Leverage, suggesting that large and highly levered financial institutions are assigned better ratings.

We now proceed to multivariate analysis in which we examine the relationship between Yield Spread and tail risk after controlling for differences in size, leverage, and other risk characteristics across institutions.

\section{Empirical Results}

\subsection{Bond Yield Spreads and Tail Risk}

We begin our empirical analysis by examining whether investors in the primary bond markets price the tail risk exposures of the financial institution issuing the bonds. To test this, we estimate the following OLS regression model:

Yield $\operatorname{Spread}_{i f t}=\alpha+\beta *$ Tail Risk $_{f, t}+\gamma * X_{f, t-1}+\rho * X_{i}+$ YearFE + InstTypeFE.

In the above equation, we use subscript ' $\mathrm{i}$ ' to denote the bond, subscript ' $\mathrm{f}$ ' to denote the issuer firm, and subscript ' $t$ ' to denote the quarter of issuance. Each observation in the regression sample corresponds to a primary bond issue. The main dependent variable of interest is the bond's Yield Spread at issuance. The main independent variable of interest is Tail Risk, which we measure using either ES or MES. We control the regression for important firm characteristics $\left(X_{f}\right)$, issue characteristics $\left(X_{i}\right)$, and macroeconomic variables that may affect Yield Spread. All the variables are defined in the Appendix. The firm characteristics that we control for are Size, Profitability, market leverage (Leverage), and book leverage (LongTermDebt_Assets). The issue characteristics that we control for are the bond's Rating, issue size, maturity, and indicator variables to identify subordinated debt, callable bonds, and 
agency debt. We also include year fixed effects in all specifications, and control for Term Spread, which is defined as the yield spread between 10-year and 1-year Treasury bonds.

We begin by estimating regression (4.1) on all financial institutions in our sample pooled together, but include institution-type fixed effects to control for differences between depository institutions, broker-dealers, insurance companies, and other financial institutions. The results of our estimation are presented in Table III. The standard errors reported in parentheses are robust to heteroskedasticity, and are clustered at the level of the institution.

The main independent variable of interest is ES in column (1) and MES in column (2). As we mentioned previously, we do not include $E S$ and $M E S$ simultaneously to avoid multicollinearity. The positive and significant coefficient on ES in column (1) indicates that yield spreads at issuance are higher for bonds issued by institutions with high tail risk. A one standard deviation increase in $E S$ increases the primary bond issuance yield by 18 basis points. However, the coefficient on $M E S$ in column (2) is statistically insignificant, and is also much smaller in magnitude than the coefficient on ES in column (1). Thus, it appears from the results in column (1) and (2) that primary bond market investors care about the institution's total tail risk, but not its systematic component of tail risk.

The coefficients on the control variables in columns (1) and (2) are broadly as expected. The positive coefficients on Rating and Maturity indicate that yield spreads are higher for lower rated bonds and longer maturity bonds, whereas the negative coefficient on Log(Issue Size) indicates that yield spreads are lower for larger issues. Examining firm characteristics, we find that yield spreads are higher for institutions with higher leverage. However, controlling for issue size, the size of the institution has no effect on yield spreads.

One possible reason for the lack of a significant association between Yield Spread and MES is that we may be over-controlling our regressions. That is, it is possible that the impact of the tail risk measures is being subsumed by Size, Leverage, Rating, and other firm-level factors, which we showed to be significantly correlated with the risk measures. To alleviate this concern, we repeat our tests from (1) and (2) after omitting all firm-level controls and the 
bond's credit rating. The results are reported in columns (3) and (4). As can be seen by comparing columns (1) and (3), the coefficient on ES does become stronger after we omit firm-level controls and rating from the regression specification, suggesting that the omitted controls are somewhat subsuming the effect of ES. However, the coefficient on MES continues to be insignificant and actually decreases in magnitude after omission of the controls.

To summarize, the results in Table III suggest that primary bond market investors care about the institution's total tail risk, but not its systematic component of tail risk.

\subsection{Bond Yield Spreads and Other Risk Measures}

A potential concern with our interpretation of the results in Table III is that MES may not be a good measure of the systematic component of tail risk. We do not believe that this is a valid concern because Acharya, Pedersen, Philippon, and Richardson (2010) show that $M E S$ is an important determinant of a financial institution's overall contribution to systemic risk, and that institutions with high $M E S$ before the onset of the financial crisis had worse stock returns during the crisis years, all else equal. Nonetheless, to alleviate this concern, we examine how primary bond yield spreads vary with other well-known risk measures, such as Volatility and Beta.

The results of our estimation are presented in Table IV. Apart from the fact that we employ different risk measures, the empirical specification and control variables in columns (1) through (3) are exactly the same as that of column (1) of Table III. That is, we control for the full set of firm-level and issue characteristics, and include year fixed effects and institutiontype fixed effects. However, to conserve space, we do not report the coefficients on the control variables.

The risk measures of interest in columns (1) and (2) are Volatility and Beta, respectively. Recall that Volatility is a measure of the institution's aggregate risk, whereas Beta is widely used as a measure of systematic risk. Consistent with our results in Table III, we find that primary bond market investors price the institution's aggregate risk (positive and significant 
coefficient on Volatility) but do not price its systematic risk (insignificant coefficient on Beta).

As we noted in Table II, ES and MES are highly correlated. To isolate the idiosyncratic component of tail risk, we construct a new risk measure, $E S_{i d i o}$, by orthogonalizing $E S$ with respect to $M E S .^{8}$ We then estimate regression (4.1) after including both $E S_{\text {idio }}$ and $M E S$ as independent variables. As can be seen from column (3), the coefficient on $E S_{\text {idio }}$ is positive and significant whereas the coefficient on MES is insignificant. Moreover, the coefficient on $E S_{\text {idio }}$ appears to be larger than the coefficient on ES in column (1) of Table III. Thus, it appears that primary bond market investors only price the idiosyncratic component of the institution's tail risk.

As in Table III, we repeat the estimations in columns (1) through (3) after omitting firmlevel characteristics and credit rating as control variables, just to make sure that these control variables are not subsuming the effect of the risk variables. As can be seen from columns (4) through (6), our qualitative results hold even after we omit these control variables. Moreover, consistent with our findings in Table III, the coefficients on Volatility and $E S_{\text {idio }}$ become stronger after the omission of the control variables, whereas the coefficient on Beta becomes significantly weaker.

Note that the results in Tables III and IV are more consistent with the moral-hazard hypothesis than the nonsalient-risks hypothesis. As per the nonsalient-risks hypothesis, yield spreads should not respond to either the idiosyncratic or the systematic component of tail risk. However, we find that although bond yield spreads do not respond to the systematic component of tail risk $(M E S)$, they do increase with the total tail risk $(E S)$ and the idiosyncratic component of tail risk $\left(E S_{\text {idio }}\right)$. On the other hand, given that bailouts are more likely in the event of a systemic failure, the fact that investors only ignore $M E S$ is consistent with the moral-hazard hypothesis.

\footnotetext{
${ }^{8}$ Formally, we obtain $E S_{\text {idio }}$ by adding the constant and the residual from the regression of $E S$ on $M E S$. We conduct the orthogonalization separately for each institution type because the sensitivity of $E S$ to $M E S$ can vary across depositories, broker-dealers, insurance companies, and other financial institutions.
} 


\subsection{Variation of Results with Bond Characteristics}

In this section, we examine how our baseline results on the association between Yield Spread and risk measures vary with key bond characteristics, such as seniority, maturity, and rating. The results of our analysis are in Table V.

In columns (1) and (2) of Table $\mathrm{V}$, we examine how the pricing of tail risk varies between senior and subordinated bonds. Absent government bailout, the loss given default should be significantly higher for subordinated bonds. Hence, it is logical to expect that the positive association between Yield Spread and tail risk measures should be stronger for subordinated bonds. To test this, we define the dummy variable $d \_S u b$ to identify subordinated bonds, and estimate regression (4.1) after including $d_{-} S u b$ and its interaction with the tail risk measures as additional regressors. The empirical specification and control variables are exactly the same as in columns (1) and (2) of Table III, although we suppress the coefficients on the control variables in order to conserve space. The positive and significant coefficient on $d_{-} S u b \times E S$ in column (1) indicates that the association between tail risk and yield spreads is indeed stronger for subordinated bonds. However, the insignificant coefficient on $d_{-} S u b \times M E S$ indicates that there is no incremental effect of $M E S$ on yield spreads for subordinated bonds over senior bonds. A more striking finding is that the sum of the coefficients on MES and $d_{-S u b \times M E S}$ is also statistically insignificant, which suggests that $M E S$ is not priced even in the case of subordinated bonds issued by financial institutions.

In columns (3) and (4), we examine how our baseline results vary with the bond's credit quality at issuance. Intuitively, we expect our results to be stronger for bonds with lower credit ratings. To test this, we define the dummy variable $d_{-}$LowGrade to identify bonds with an S\&P credit rating of "A" or worse at issuance (i.e., Rating $\geq 5$ ), and interact this with the tail risk measures. ${ }^{9}$ The positive coefficients on the interaction terms $d_{-}$LowGrade $\times E S$ and $d_{-}$LowGradex MES indicate that the effect of tail risk on yield spreads is indeed stronger for

\footnotetext{
${ }^{9}$ High-grade bonds (defined as those with credit rating of AAA or AA) constitute roughly $33 \%$ of our sample, medium-grade bonds (defined as those with credit rating between $\mathrm{A}$ and $\mathrm{BBB}$ ) constitute $63 \%$ of our sample, and speculative-grade bonds (i.e., credit rating worse than $\mathrm{BBB}$ ) constitute the remaining $4 \%$.
} 
low grade bonds. These results are inconsistent with the nonsalient-risks hypothesis as yield spreads respond to both the idiosyncratic and systematic component of tail risk.

In columns (5) and (6), we examine whether the effect of tail risk on yield spreads is stronger for longer maturity bonds. There are two reasons to expect that the effect should be stronger for longer maturity bonds. First, there is more uncertainty in the long run than in the short run. Second, given that financial institutions rely heavily on short-term debt, long-term bondholders are also exposed to the risk that the institution may not be able to rollover or refinance its short-term debt ("rollover risk"). To test this, we define the dummy variable $d_{-}$LongMat to identify bonds with stated maturity of 10 years or more. We then estimate our baseline regressions after including $d_{-}$LongMat and its interaction with the tail risk measures as additional regressors. As can be seen from the insignificant coefficients on $d_{\_}$LongMat $\times E S$ and $d_{-}$LongMat $\times M E S$, we fail to detect any incremental effect of tail risk on primary yield spreads for longer maturity bonds. Moreover, the sum of the coefficients on $M E S$ and d_LongMat $\times$ MES in column (4) is also statistically insignificant, which suggests that $M E S$ is not priced for long maturity bonds.

\subsection{Variation of Results with Firm Characteristics}

Next, we examine how our baseline results on the association between Yield Spread and tail risk measures vary with important firm characteristics, such as size, leverage, and implicit bailout expectations. The results of our analysis are in Table VI.

We begin with the effect of firm size. As per the moral-hazard hypothesis, the relationship between Yield Spread and tail risk should be weaker for large institutions, which are more likely to be considered systemically important and qualify for implicit too-big-to-fail guarantees. To test this, we define the dummy variable $d \_$Large to identify firms that are larger than the median size by the book value of assets in the universe of all the financial firms in COMPUSTAT. ${ }^{10}$ We then estimate our baseline regressions after including $d_{-}$Large and

\footnotetext{
${ }^{10}$ This classification yields 144 small firms and 160 large firms. However, the large firms contribute to more
} 
its interactions with tail risk measures as additional regressors. The negative and significant coefficient on $d_{-}$Large $\times E S$ in column (1) indicates that the incremental effect of ES on Yield Spread is significantly weaker for large institutions. However, the sum of coefficients on ES and $d_{-}$Large $\times E S$ is still positive and significant, which suggests that yield spreads increase with total tail risk even for large financial institutions. On the other hand, the coefficients on MES and d_Large $\times M E S$ in column (2), as well as the sum of these coefficients are all statistically insignificant. This indicates that yield spreads do not vary with $M E S$ regardless of the institution's size.

In columns (3) and (4), we examine if our results vary with the level of the institution's leverage. As with size, we define the dummy variable $d \_$HighLeverage to identify institutions whose market leverage exceeds the median leverage in the universe of all the financial firms in COMPUSTAT. As expected, the positive and significant coefficient on $d_{-}$Leverage signifies that firms with higher leverage have higher bond yield spreads, all else equal. However, we fail to find any incremental effect of tail risk on yield spreads for institutions with high leverage.

An interesting class of institutions in our sample are the GSEs such as Fannie Mae and Freddie Mac. Although bonds issued by GSEs carry no explicit government guarantee of creditworthiness, there is a perception of an implicit guarantee because it is widely believed that the government will not allow such important institutions to fail or default on their debt. ${ }^{11}$ Hence, as per the moral-hazard hypothesis, we should also expect the relationship between Yield Spread and tail risk measures to be weaker for GSEs. We examine this in columns (5) and (6) where we interact the tail risk measures with $d \_$Agency, a dummy variable that identifies GSEs. The strong negative and significant coefficients on $d_{-}$Agency $\times E S$ and $d_{-}$Agency $\times M E S$ indicate that the effect of tail risk exposure on yield spreads is indeed much weaker for bonds issued by GSEs.

As a further robustness check, in unreported results, we also compare financial firms and

than three-quarters of the issuance sample while the remainder comes from the smaller firms.

${ }^{11}$ According to estimates by the Congressional Budget Office and the Treasury Department in 1997, GSEs saved about $\$ 2$ billion per year in funding costs because of this implicit guarantee. 
industrial firms by employing the nearest-neighborhood (NN) matching technique (see Abadie, Drukker, Herr, and Imbens (2004)) to match debt issued by financial firms to debt issued by non-financials (industrial firms). We conduct an exact matching on the subordination status, callability feature, and year of origination, and then use the NN matching on the remaining controls in the bond yield spread regression model, namely, Rating, LogAssets, Profitability, LongTermDebt_Assets, Leverage, LogIssueSize, and Maturity. ${ }^{12}$ To ensure that our results are not sensitive to the sample of matched counterfactuals, we match each bond offering by a financial institution (treated sample) with three bond offerings by non-financial firms (control sample). We find that investors do not price the systematic tail risk exposures of financial institutions for their senior or their subordinated debt issuances. Overall, our matched sample analysis gives further credence to the moral-hazard hypothesis that investors choose to ignore tail risks for certain types of firms based on their expectation of future bailouts.

\section{Additional Robustness Tests}

As we noted in the introduction, there are two potential reasons why primary bond market investors may not price an institution's tail risk. It may be that bond market investors are subject to moral hazard because, given the systemic importance of the financial sector, they rationally anticipate taxpayer-funded bailouts in the event of large losses. Alternatively, it may be that investors neglect low-probability nonsalient risks, in general, and are caught unaware when the debt that they had considered safe turns out to be risky (Gennaioli, Shleifer, and Vishny (2012)). In this section, we conduct additional tests aimed at distinguishing between these competing hypotheses.

\footnotetext{
${ }^{12}$ Optimal matching resulted in $100 \%$ matching on the subordinated and callable dummy, and $91 \%$ on offering year of the bond. As the optimal matching on offering year is not exact, we include year fixed effects in our regressions.
} 


\subsection{Variation of Results Across Institution Types}

One way to distinguish between the moral-hazard hypothesis and the nonsalient-risk hypothesis is to examine how the pricing of tail risk varies across different types of financial institutions. Certain types of financial institutions, such as depositories and GSEs, are more likely to be considered systemically important because the failure of such institutions imposes a large negative externality on the real economy. Such institutions are also more likely to receive government bailouts if a negative event materializes. Thus, as per the moral-hazard hypothesis, the relationship between bond yield spreads and tail risk should be weaker for depository institutions compared with other types of financial institutions.

To test this idea, we now estimate regression (4.1) separately for bonds issued by each institution type. The results of our estimation are presented in Panel A of Table VII. We estimate the regressions separately on the subsamples of bonds issued by depository institutions (columns (1) and (2)), broker-dealers (columns (3) and (4)), insurance companies (columns (5) and (6)), and other financial institutions (columns (7) and (8)). We control these regressions for the full set of firm and bond characteristics as in Table III, and also include year fixed effects. However, to conserve space, we do not report the coefficients on the control variables.

As can be seen, the results in Panel A highlight a striking difference in the pricing of tail risk between bonds issued by depository institutions and bonds issued by all other types of financial institutions. The insignificant coefficients on ES and MES in columns (1) and (2) indicate that the cost of debt for depository institutions does not vary with their exposure to tail risk. On the other hand, we find a positive and significant association between Yield Spread and tail risk measures for all other institution types, except for the category of other financial institutions for which the coefficient on $M E S$ is positive but statistically insignificant. The lack of significance on MES in column (8) may be driven by bonds issued by GSEs, which are included in the category of other financial institutions. As we showed in Panel B of Table VI, the relationship between bond yield spreads and tail risk is significantly weaker in case of bonds issued by GSEs. 
Our results in Panel A cast doubt on the idea that primary bond markets can provide effective market discipline to depository institutions. One particular category of bonds that bank regulators and supervisors rely on to enhance market discipline are subordinated bonds, which are meant to act as loss-bearing instruments and are thus treated as part of regulatory capital. As we noted in the discussion following Table I, depository institutions are by far the largest issuers of subordinated bonds. In Panel B of Table VII, we separately examine whether the pricing of tail risk varies between subordinated and senior bonds for depository institutions (in columns (1) and (2)) and for all other types of financial institutions (in columns (3) and (4)).

The positive and significant coefficient on $d_{-} S u b \times E S$ in column (1) indicates that in the case of bonds issued by depository institutions, the relationship between Yield Spread and ES is indeed stronger for subordinated bonds. However, the coefficient on $E S$ is itself negative, although not statistically significant. Moreover, the sum of coefficients on ES and $d \_S u b \times E S$ is insignificant, which indicates that tail risk is not priced even in the case of subordinated bonds issued by depository institutions. In column (2), we find that the coefficients on MES and $d_{-} S u b \times M E S$, as well as the sum of these coefficients, are all statistically insignificant. That is, systematic tail risk $M E S$ is not priced either for senior or subordinated bonds issued by depository institutions.

Turning to the non-depository institutions, we can see that the coefficients on $d \_S u b \times E S$ in column (3) and $d_{-} S u b \times M E S$ in column (4) are both positive but are not statistically significant at the conventional $10 \%$ level (the $t$-statistics of 1.61 and 1.49, respectively, are lower than the cutoff value of 1.652). However, the coefficient on $E S$ as well as the sum of coefficients on $E S$ and $d_{-} S u b \times E S$ in column (3) are both statistically significant, which indicates that total tail risk is priced for both senior and subordinated bonds issued by non-depository institutions. The same is true for systematic tail risk MES in column (4).

Overall, the results in Table VII indicate that the pricing of tail risk in the primary bond market varies between depository institutions and non-depository institutions. The result that 
neither $E S$ nor $M E S$ is priced for bonds issued by depository institutions is consistent with the moral-hazard hypothesis, because depository institutions are more likely to be considered systemically important and benefit from implicit government guarantees. In unreported tests, we verify that the qualitative results in Table VII are robust to the exclusion of firm-level characteristics and credit rating as control variables; that is, we verify that the effect of tail risk is not being subsumed by Size, Leverage, and Rating of depository institutions.

\subsection{Political Connectedness and the Pricing of Tail Risk}

In this section, we focus on cross-sectional variation in bailout expectations across financial institutions. One such source of cross-sectional variation is the political connectedness of financial institutions. If politically connected institutions are more likely to receive government bailouts, then we expect the relationship between bond yield spreads and tail risk measures to be weaker for better connected institutions.

We measure political connectedness using information on lobbying expenditures by financial institutions obtained from the Center for Responsive Politics (CRP), which compiles data from lobbying disclosure reports filed with the Secretary of the Senate's Office of Public Records (SOPR). ${ }^{13}$ This data is available from 1998 through the most recent quarter. We hand-match lobbying records with our data set by firm name and broad industry classification. We measure political connectedness using two variables: a dummy variable d_PoliticalConnection, which identifies financial institutions that have ever lobbied the government; and Log(Lobby Expenditure), which is the natural logarithm of the amount of total lobbying expenditure by the institution since the data became available in 1998.

As per our definition of $d_{-}$PoliticalConnection, $53 \%$ of the institutions in our sample are politically connected, and include large institutions that were bailed out during the recent

\footnotetext{
${ }^{13}$ This data is also publicly available for download on SOPR's website. As per the lobbying disclosure act of 1995 , firms that hire lobbyists are required to provide a good-faith estimate rounded to the nearest $\$ 20,000$ of all lobbying-related expenditures in each six-month period. An organization that spends less than $\$ 10,000$ in any six-month period does not have to state its expenditures. In those cases, the Center treats the figure as zero.
} 
financial crisis; e.g., Bear Stearns, AIG, Citigroup, Merrill Lynch, Bank of America, JP Morgan, CIT Group, Freddie Mac, and Fannie Mae among others. The average lobbying amount per year for our sample of firms is close to $\$ 1.8$ million. Depositories on average have the highest lobbying amount per year, as well as the highest percentage of politically connected firms, followed by broker-dealers. In general, there seems to be a positive correlation between our measures of political connectedness and bailout probability (Faccio et al. (2006)). A simple correlation analysis shows that our measures of political connectedness are positively correlated with firm assets and leverage, which implies that larger institutions lobby the government more. Similarly, the correlation between Yield Spread and our political connections measures are negatively correlated, which indicates that politically connected firms seem to enjoy a lower cost of capital.

To test whether the pricing of tail risk varies with the institutions' political connectedness, we estimate regression (4.1) after including our measures of political connectedness and their interactions with the tail risk measures as additional regressors. We can estimate this regression only for the 1998 to 2010 period as the data on lobbying expenditures is available only after 1998. The results of our analysis are presented in Table VIII. The empirical specification and control variables are exactly the same as in Table III although we suppress the coefficients on control variables in order to conserve space.

The negative and significant coefficients on d_PoliticalConnection $\times E S$ and Log(Lobby Expenditure) $\times E S$ in columns (1) and (3), respectively, indicate that the relationship between Yield Spread and tail risk is indeed weaker for politically connected institutions. On the other hand, although the coefficients on d_PoliticalConnection $\times M E S$ and Log(Lobby Expenditure) $\times M E S$ in columns (2) and (4), respectively, are negative, they are not statistically significant. Hence, we cannot conclude that the pricing of systematic tail risk varies between politically-connected and non-connected financial institutions.

If the entire financial sector is expected to be bailed out during a crisis, then the pricing of a firm's systematic tail risk $M E S$ may vary less with its political connectedness during such 
crisis periods. However, unconditionally, regardless of the state of the economy, one can expect the probability of bailout to be higher for politically connected firms. As a robustness check, we present a subsample analysis in columns (5) to (8) for the non-crisis period extending from 2001:Q2 to 2008:Q2, which spans a crisis-free period immediately after the LTCM and dotcom crises and immediately prior to the recent financial crisis. In line with our expectation, not only do we find that $M E S$ is mispriced for politically connected firms, but the severity of mispricing of $E S$ has also increased. Overall, this analysis confirms that the pricing relevance of tail risks decreases with an increase in bailout probability as measured by political connectedness. This is again consistent with the moral-hazard hypothesis.

Overall, the results in Table VIII provide more evidence in support of the moral-hazard hypothesis by highlighting that primary bond market investors are less likely to price the tail risk exposures of politically-connected institutions.

\subsection{Pricing of Tail Risk Around Crisis Periods}

In the previous section, we used political connectedness to identify the cross-sectional variation in bailout expectations across firms. Another way to distinguish between the moral-hazard hypothesis and the nonsalient-risks hypothesis is to examine how the association between Yield Spread and the tail risk measures varies around crisis periods. In general, a crisis can affect the pricing of tail risk in two ways. In the absence of bailout expectations, a crisis may serve as a reminder of the existence of tail risks, and thus strengthen the relationship between Yield Spread and the tail risk. However, if the crisis triggers large-scale bailouts of troubled institutions, that may weaken the relationship between Yield Spread and the tail risk.

To better understand these effects, we focus on three crisis events that occurred during our sample period: the failure and bailout of LTCM in August 1998, the dotcom crash of March 2000, and the recent financial crisis in March 2008. Note that unlike the dotcom crash, which was largely confined to the technology sector, the LTCM crisis and the recent financial crisis adversely affected the financial sector and triggered government bailouts of troubled 
institutions. We exploit this key difference to understand the extent to which our results are being driven by changes in expectations of future bailouts. For each of these crisis events, we construct a sample of bond issuances by all financial institutions that occurred in a two-year (i.e., eight calendar quarters) window around the crisis event, and divide this into pre-crisis and post-crisis windows of four calendars quarters each. ${ }^{14}$ We then compare how the pricing of tail risk varies between the pre-crisis and post-crisis samples.

The results of our analysis are summarized in Table IX. In columns (1) and (2), we examine the effect of the LTCM crisis that occurred during August and September of 1998. The LTCM bailout was announced on September 23, 1998 when 14 financial institutions agreed to a $\$ 3.6$ billion recapitalization under the supervision of the Federal Reserve. Accordingly, we use the sample of bonds issued during the two-year period from 1997:Q4 to 1999:Q3 surrounding this crisis event; the sample consists of 154 bond offerings. In this sample, we define the dummy variable $d \_L T C M$ to identify bonds issued between 1998:Q4 and 1999:Q3, that is, after the LTCM bailout was announced. We then estimate regression (4.1) after including $d_{-} L T C M$ and its interactions with the tail risk variables as additional regressors. The empirical specification and control variables are otherwise the same as in Table III, but with one important difference: we exclude the year dummies, and instead use the specific crisis dummy to understand how the pricing of tail risk changed pre- and post-crisis. We suppress the coefficients on the control variables in order to conserve space.

The positive and significant coefficients on $d_{-} L T C M$ in columns (1) and (2) indicate that primary bond yield spreads of financial firms increased significantly in the immediate aftermath of the LTCM crisis. However, the negative and significant coefficients on $d_{-} L T C M \times E S$ and $d_{-} L T C M \times M E S$ in columns (1) and (2), respectively, indicate that the relationship between Yield Spread and tail risk was significantly weaker in the immediate aftermath of the LTCM crisis. Moreover, the sum of the coefficients on ES and $d_{-} L T C M \times E S$ in column (1) is

\footnotetext{
${ }^{14}$ Choosing a two-year window around the crisis provides a reasonable sample size for our analysis without introducing other confounding events, thus allowing for cleaner interpretation of results. We must note that it is not feasible to conduct these tests separately for each institution type as the sample size for each institution type would be very small. Hence, we conduct these tests for all financial institutions pooled together, but include institution-type fixed effects in the regression specification.
} 
insignificant, and so is the sum of the coefficients on $M E S$ and $d_{-} L T C M \times M E S$ in column (2). These indicate that tail risk was not priced at all in the immediate aftermath of the LTCM crisis.

We examine the effect of the recent financial crisis in columns (3) and (4). The main events of the financial crisis occurred during mid-September to early October of $2008 .{ }^{15}$ Accordingly, to understand the impact of the financial crisis, we use the sample of bonds issued during the two-year period from 2007:Q4 to 2009:Q3. In this sample, we use the dummy variable $d \_$FinCrisis to identify bonds issued between 2008:4Q and 2009:Q3, which denotes the post-crisis period. As can be seen from columns (3) and (4), the impact of the financial crisis was very similar to that of the LTCM crisis: although there was an across-the-board increase in primary bond yield spreads for all financial institutions following the crisis (positive coefficient on $d \_$FinCrisis), the relationship between yield spreads and tail risk was also significantly weaker after the crisis as evidenced by the negative and significant coefficients on $d \_$FinCrisis $\times E S$ and $d \_$FinCrisis $\times$MES .

Finally, in columns (5) and (6), we study the effect of the dotcom crisis, which was triggered by the collapse of the NASDAQ-100 Index on March 10, 2000. Accordingly, we use the sample of bonds issued in the two-year period from 1999:Q2 to 2001:Q1. In this sample, the dummy variable d_Dotcom identifies bonds issued between the period 2000:Q2 and 2001:Q1, the period right after the dotcom bubble burst on March 10, 2000. As with the LTCM crisis and the financial crisis of 2008, we find that there was an across-the-board increase in primary bond yield spreads of financial institutions in the immediate aftermath of the dotcom crisis (positive and significant coefficient on $d_{-}$DotCom). However, in stark contrast to the other two crises, the coefficients on $d_{-}$DotCom $\times E S$ and $d \_D o t C o m \times M E S$ are statistically insignificant, which suggests that there was no difference in the pricing of tail risk in the primary bond markets in the immediate aftermath of the dotcom crisis. This could be due to the fact that

\footnotetext{
${ }^{15}$ The collapse of Lehman Brothers and the collapse and bailout of AIG occurred on September 15 and 16, 2008, triggering widespread panic and a liquidity crisis that required the intervention of the U.S. government and the Federal Reserve. In the next few weeks, other financial institutions including Merrill Lynch, Fannie Mae, Freddie Mac, Washington Mutual, Wachovia, and Citigroup were either acquired under duress, or were subject to government takeover.
} 
the dotcom crash did not change bond market investors' expectations of future bailouts of financial institutions.

Overall, the evidence in Table IX lends more support to the moral-hazard hypothesis over the nonsalient-risks hypothesis.

\subsection{Do Rating Agencies Account for Tail Risk Exposures?}

Investors may rely on rating agencies to price tail risk, as rating agencies specialize in determining creditworthiness of firms. For example, a rating agency may be better positioned to judge the quality of loans and other non-traded assets on a bank's balance sheet. Rating agencies also have access to a firm's private information as they were exempt from the Fair Disclosure Regulation (Reg FD) during our sample period. If rating agencies are also subject to the aforementioned bailout moral hazard problem then they may not price tail risk. Bond investors, who may rely on rating agencies to price tail risks, will consequently not price it too. On the other hand rating agencies may price tail risk and investors might rationally choose to ignore them. To investigate this issue we run an ordered probit model with Rating as the dependent variable, and $E S$ and $M E S$ as the key independent variables of interest. We include all the control variables in equation (4.1) except of course Rating itself. The results of our estimation are presented in Panel A of Table X.

In columns (1) and (2), we estimate the regression separately on the subsample of bonds issued by depository institutions. Although we find a positive association between Rating and total tail risk $(E S)$, we fail to find any association between Rating and systematic tail risk $(M E S)$. Interestingly, while rating agencies appear to price $E S$, investors seem to ignore it as

shown in Table VII. In columns (3) and (4), we estimate the regression separately on the subsample of bonds issued by broker-dealers. In this subsample, we fail to find any significant association between Rating and either tail risk or systematic tail risk. In contrast, even though rating agencies seem to ignore the tail risk exposures of broker-dealers, primary bond market investors as shown in Table VII seem well aware of these risks and do price them. When 
we estimate the regression on bonds issued by insurance companies (columns (5) and (6)) and other financial institutions (columns (7) and (8)), we find a positive association between Rating and both tail risk measures, which is particularly strong for bonds issued by insurance companies.

Next, we examine how the association between Rating and the tail risk measures varies with bonds' seniority status. As in the previous section, we repeat our regression in Panel A after including the interaction terms $d_{-} S u b \times E S$ and $d_{-} S u b \times M E S$, where $d_{-} S u b$ is an indicator variable that identifies subordinated bonds. The results of the estimation are presented in Panel B. The positive and significant coefficient on $d \_S u b$ indicates that subordinated bonds are assigned lower ratings, all else equal, which is to be expected because the loss given default should be higher for these bonds. However, surprisingly, there is no adverse incremental effect of tail risk on the credit ratings of subordinated bonds. As can be seen, the coefficients on $d \_S u b \times E S$ and $d \_S u b \times M E S$ are mostly insignificant; in fact, we find a negative and significant coefficient on $d \_S u b \times E S$ in column (1). In a separate row, we also report the statistical significance on the sum of coefficients on the tail risk measure and its interaction term with the $d \_S u b$ dummy. Overall, these coefficients are positive and significant for depositories whereas they are insignificant for the rest of the financial firms suggesting that rating agencies account for tail risk for subordinated debt issued by depositories although not incrementally over senior bonds.

To summarize, the results in Table $\mathrm{X}$ highlight interesting differences in how credit rating agencies rate new bond issuances by different types of financial institutions compared with investors. In particular, rating agencies do not seem to account for tail risk exposures of broker-dealers and the systematic tail risk exposure of depository institutions. More strikingly, although subordinated bonds are assigned lower credit ratings, there is no additional adverse impact of the institution's tail risk on the credit ratings assigned to subordinated bonds. Again, to ensure we are not over-controlling our regressions, we repeat all of our tests from Panels A and B after omitting these firm-level factors as controls. The results of these 
robustness tests are however not reported and our qualitative results from Panels A and B are unchanged when we omit these additional controls. The only noticeable difference is that the coefficient on $M E S$ is significantly lower for these repeat tests of Panels A and B and all of the sum of coefficients on the tail risk measure and its interaction term with the $d_{-} S u b$ dummy are small and statistically insignificant. Overall, the ordered probit rating regression results indicate that it is not the investors' reliance on rating agencies that leads to the mispricing of tail risk.

\section{Conclusion}

In the aftermath of the recent financial crisis, there is an increased focus on containing tail risk and systematic risk exposure of financial institutions. One recurring idea in financial sector regulation is for regulators to increase their reliance on "market discipline" in controlling institutions' risk exposure. However, market discipline is effective only if investors price the risk exposure of financial institutions. In the recent U.S. subprime financial crisis, largescale government interventions were enacted, which included bailouts designed to prevent the financial industry from a potential system-wide breakdown. However, a consequence of implied government guarantees and bailouts for financial institutions is a weakening of market discipline. Investors can be subject to moral hazard and may not rationally price an institution's exposure to tail risks.

In this paper, we use a large sample of bond issuances by U.S. financial institutions during the 1990 to 2010 period to examine whether bond market investors price the tail risk exposure of financial institutions. We find that primary bond yield spreads increase with institutions' own tail risk (expected shortfall) but do not respond to their systematic tail risk (marginal expected shortfall), even in the case of subordinated bonds. When we distinguish between different types of financial institutions, we find a striking result that primary bond yield spreads of depository institutions do not respond to tail risk for either senior bonds or subordinated bonds. On the other hand, primary bond yield spreads of broker-dealers and 
insurance companies respond to both total tail risk and systematic tail risk.

There are two potential explanations for why bond market investors may neglect tail risk exposure of financial institutions. It may be that bond market investors are subject to moral hazard because they rationally expect to be bailed out by the government if a negative tail event materializes. Alternatively, it may be that investors neglect low-probability nonsalient risks are are caught unaware when the assets that they had considered to be safe turn out to be risky. Consistent with the moral-hazard hypothesis, we find that systematic tail risk is not priced in situations where ex-ante bailout expectations are higher: that is, for depositories and government-sponsored entities (GSEs), large institutions, and politically connected firms. Moreover, bond investors' concern for tail risk seems to have weakened in the immediate aftermath of financial crises (such as LTCM and the recent financial crisis) that involved government bailouts of financial institutions.

Overall, our results point to moral hazard in the primary bond markets due to implicit bailout guarantees and cast doubt on the idea that market discipline can be effective in controlling the tail risk exposures of depository institutions. 


\section{References}

Abadie, A., D. Drukker, J. L. Herr, and G. W. Imbens (2004). Implementing matching estimators for average treatment effects in stata. Stata journal 4, 290-311.

Acharya, V. and T. Yorulmazer (2007). Too many to fail: An analysis of time-inconsistency in bank closure policies. Journal of Fixed Income 16, 1-31.

Acharya, V. V., D. Anginer, and A. J. Warburton (2013). The End of Market Discipline? investor Expectations of Implicit State Guarantees. NYU Working Paper.

Acharya, V. V., L. H. Pedersen, T. Philippon, and M. Richardson (2010, November). Measuring systemic risk. NYU Working Paper.

Avery, R., T. Belton, and M. Goldberg (1988). Market discipline in regulating bank risk: New evidence from the capital markets. 20, 597-610.

Bernardo, A., E. Talley, and I. Welch (2011). A model of optimal government bailouts. Working Paper.

Bordalo, P., N. Gennaioli, and A. Shleifer (2012). Salience theory of choice under risk. Quarterly Journal of Economics 127(3), 1243-1285.

Cargill, T. F. (1989). CAMEL Ratings and the CD Market. Journal of Financial Services Research, 347-358.

Chava, S., P. Kumar, and A. Warga (2010). Managerial agency and bond covenants. Review of Financial Studies 23(3), 1120-1148.

Coval, J. D., J. W. Jurek, and E. Stafford (2009). The economics of structured finance. The Journal of Economic Perspectives 23(1), 3-26.

Ellis, D. M. and M. J. Flannery (1992). Does the debt market assess large banks' risk? Journal of Monetary Economics 30, 481-502.

Faccio, M., R. W. Masulis, and J. J. McConnell (2006). Political Connections and Corporate Bailouts. Journal of Finance 61, 2597-2635.

Farhi, E. and J. Tirole (2011). Collective moral hazard, maturity mismatch and systemic bailouts. American Economic Review 102(1), 60-93.

Flannery, M. J. and S. M. Sorescu (1996). Evidence of bank market discipline in subordinated debenture yields: 1983-1991. Journal of Finance 51, 1347-1377.

Gennaioli, N., A. Shleifer, and R. Vishny (2012). Neglected risks, financial innovation, and financial fragility. Journal of Financial Economics 104, 452-468.

Gorton, G. and A. Santomero (1990). Market discipline and bank subordinated debt. 22, 119-128. 
Hannan, T. H. and G. A. Hanweck (1988). Bank insolvency risk and the market for large certificates of deposit. 20, 203-212.

Hansen, L. P. (2011). Challenges in identifying and measuring systemic risk. NBER Working Paper.

Hoenig, T. M. (2008, March). Perspectives on the recent financial market turmoil. Remarks at the 2008 Institute of International Finance Membership Meeting, Rio de Janeiro, Brazil, March 5.

Jarrow, R., L. Li, M. Mesler, and D. van Deventer (2007). CDO valuation: Fact and fiction. The Definitive Guide to CDOs, Risk Publications.

Kashyap, A. K., R. G. Rajan, and J. C. Stein (2008). Rethinking capital regulation. NBER working paper.

Kelly, B. T., H. Lustig, and S. Van Nieuwerburgh (2011). Too-systemic-to-fail: What option markets imply about sector-wide government guarantees. NBER Working Paper.

Rajan, R. G. (2005). Has financial development made the world riskier? Proceedings of the Jackson Hole Conference organized by the Kansas City Fed.

Ratnovski, L. and G. DellAriccia (2012). Bailouts, contagion, and moral hazard. Working Paper.

Strahan, P. E. (2013). Too big to fail: Causes, consequences, and policy responses. Annual Review of Financial Economics 5(1), 43-61. 


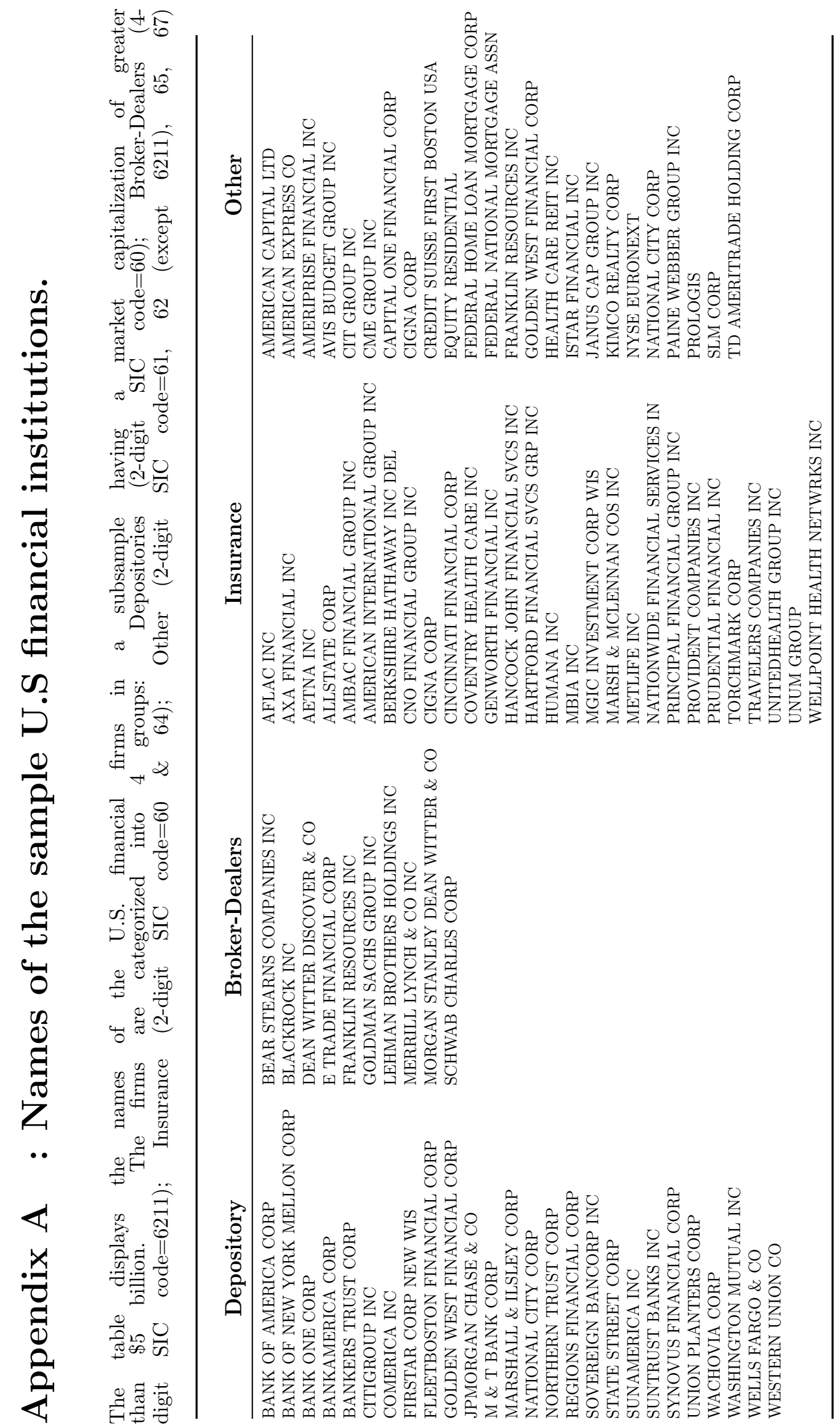




\section{Appendix B : Bond yields regression variables.}

- Total debt $=$ long-term debt + short-term debt

- Market value of assets $=($ stock price $\times$ shares outstanding $)$ at bond issuance + Book value of debt

- Term spread = yield spread between the 10- and 1-year treasury bonds

- Profitability $=$ operating income after depreciation $\div$ sales

- Long-term debt to total assets (book leverage) $=$ long-term debt $\div$ book value of total assets

- Leverage (market leverage $)=$ market value of assets $\div$ market value of equity 


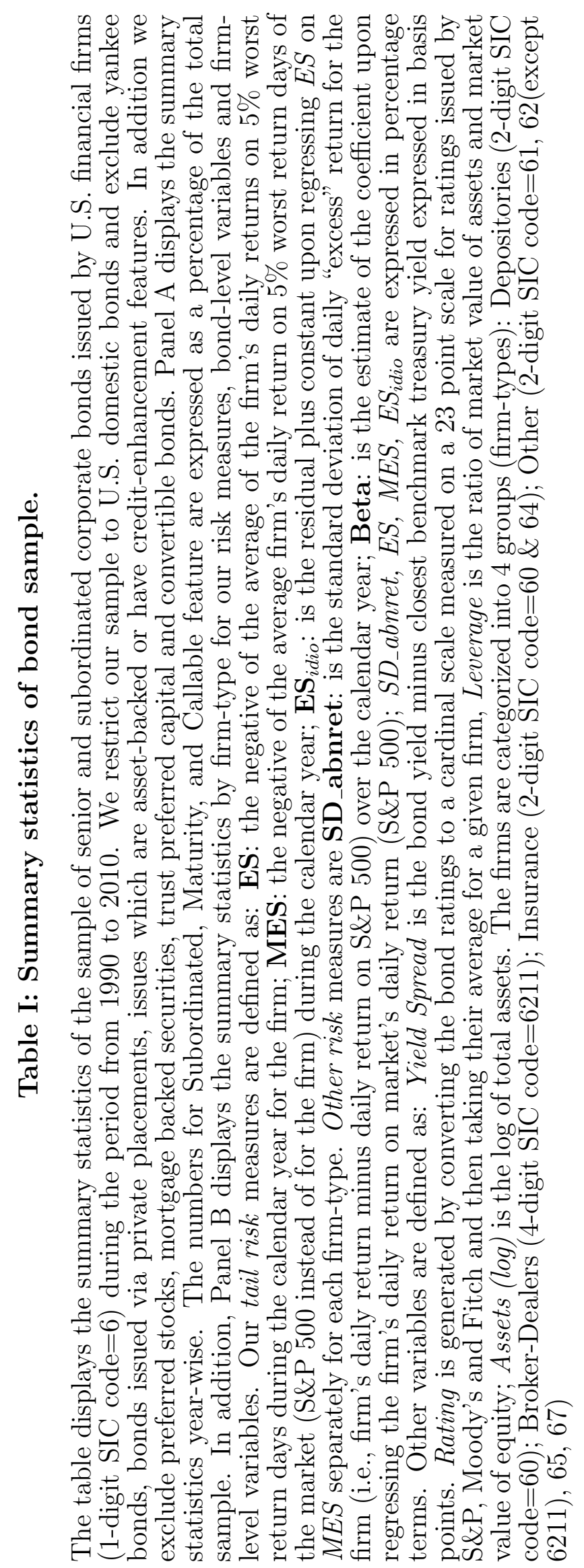




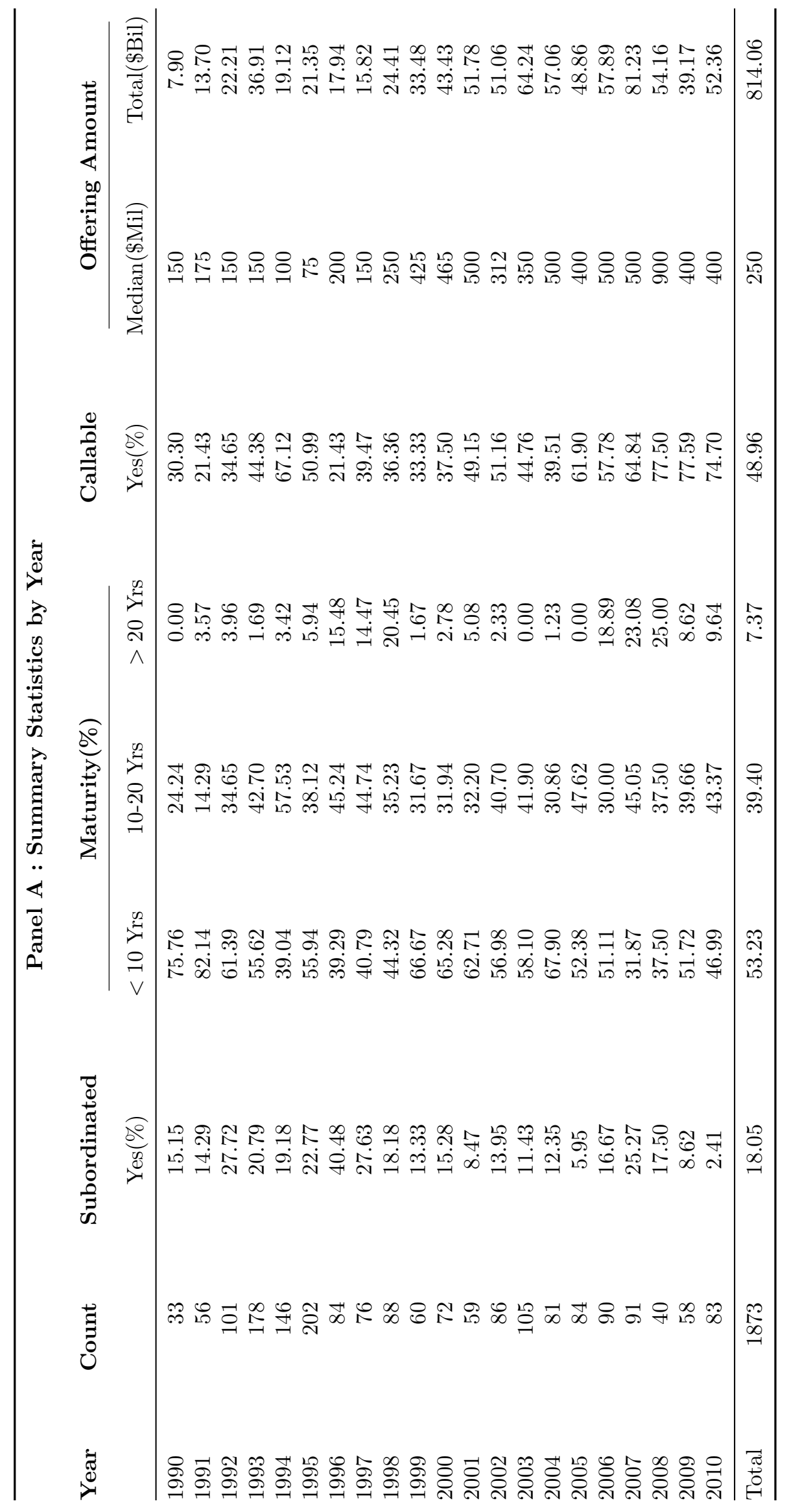




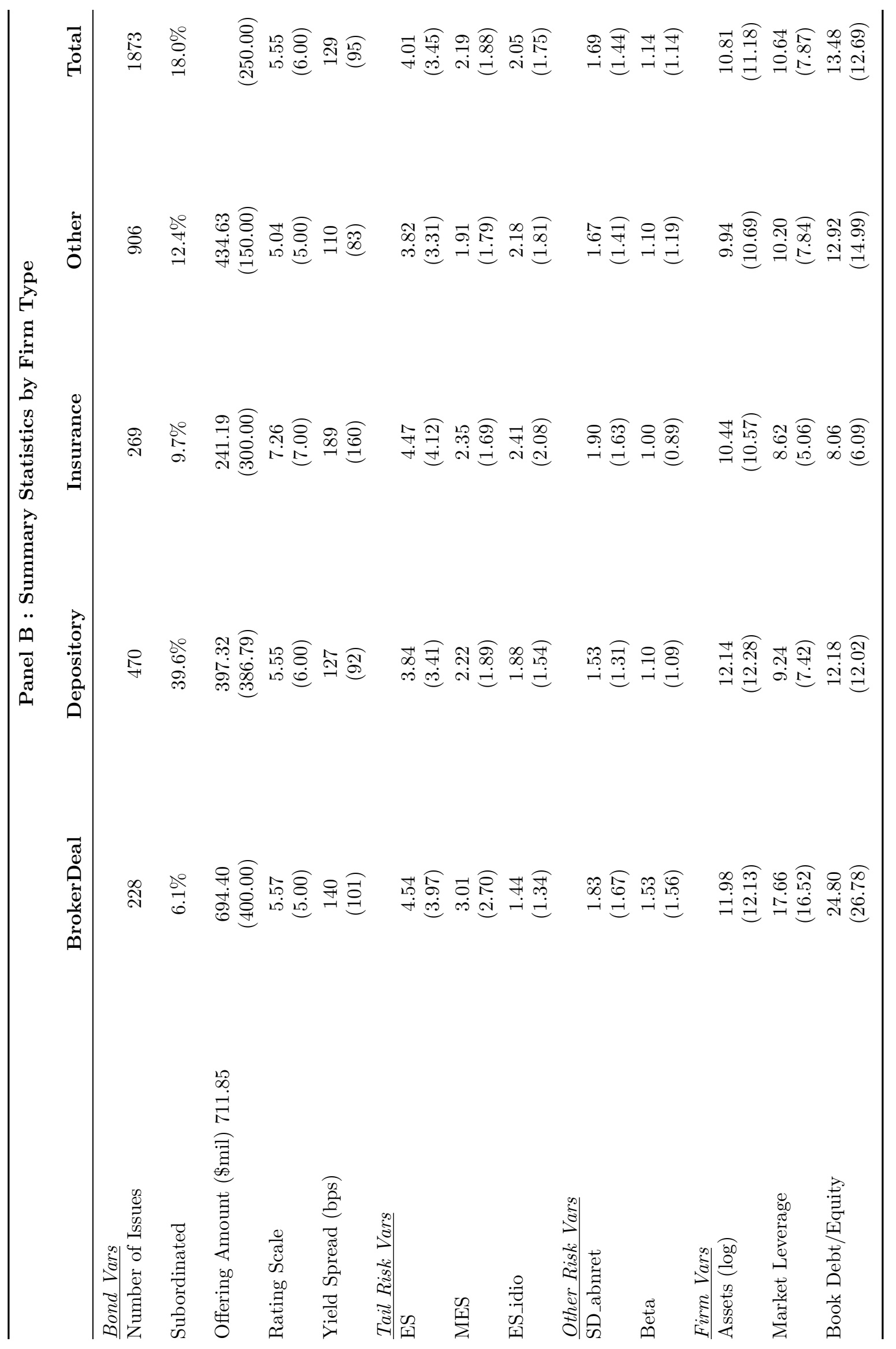




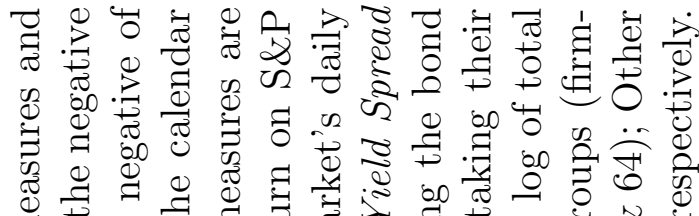

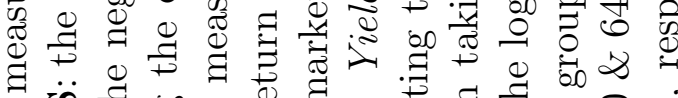

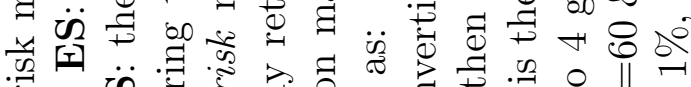

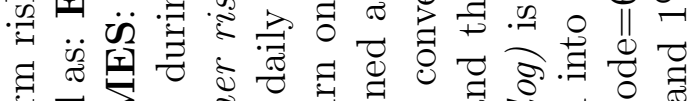

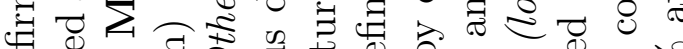

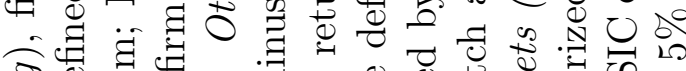
है

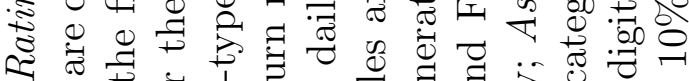
च क ₹ की

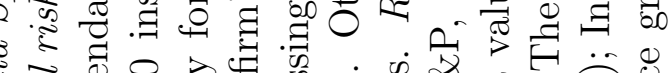

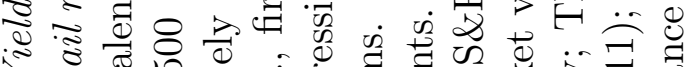
他 ๑

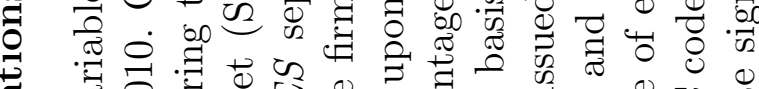

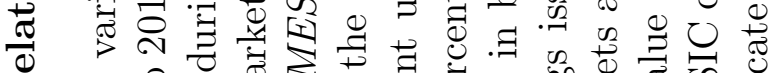

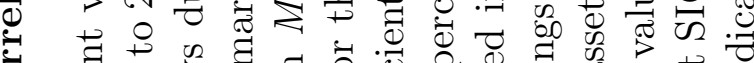

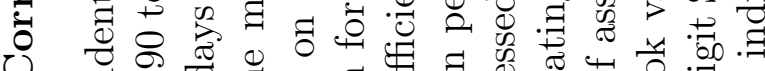

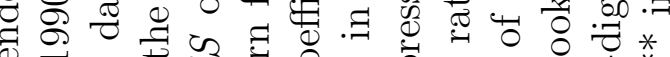

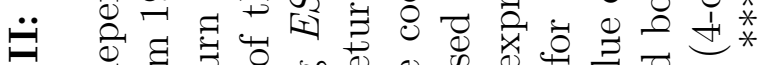

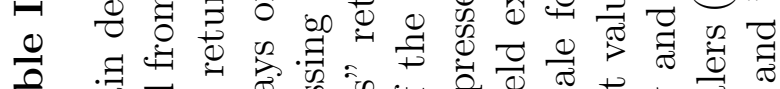

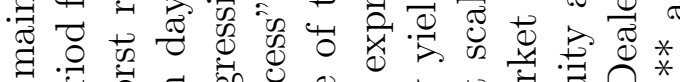

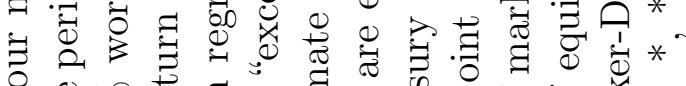

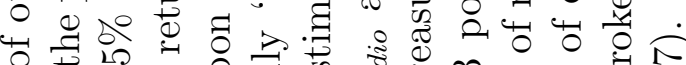
क bo

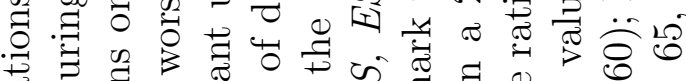

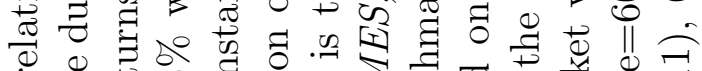

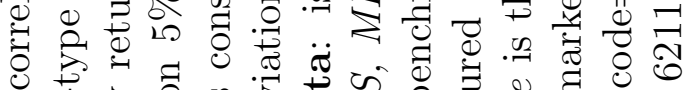
8

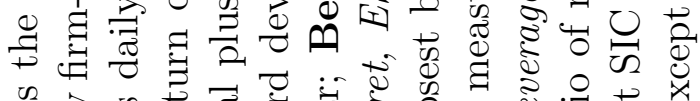

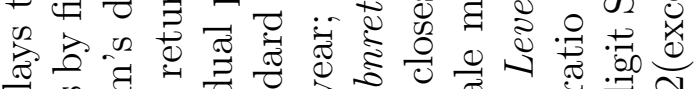
क क

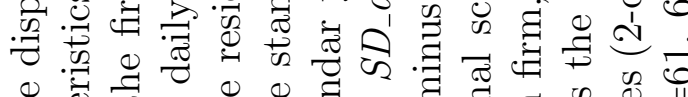

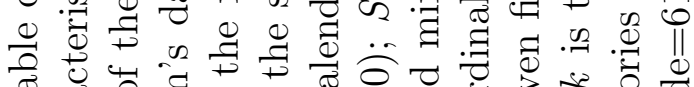

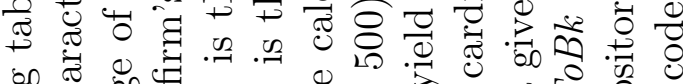

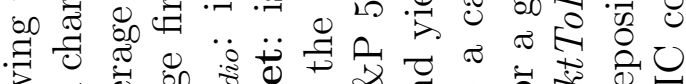

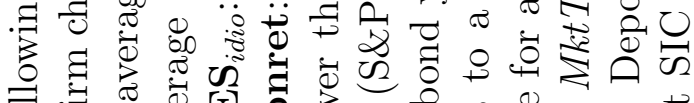

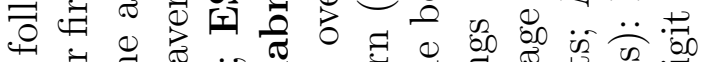

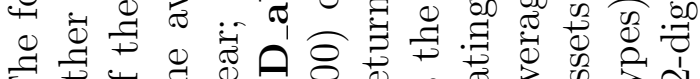

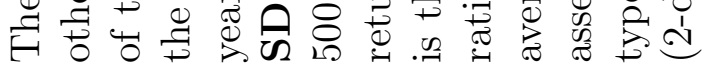




\section{Table III: Bond Yield Spreads and Tail Risk}

The following table displays the primary bond yield regressions with dependent variable as bond yield minus the closest benchmark treasury yield expressed in basis points on firm tail-risk measures and other firm and bond characteristics during the period from 1990 to 2010. Our tail risk measures are defined as: ES: the negative of the average of the firm's daily returns on $5 \%$ worst return days during the calendar year for the firm; MES: the negative of the average firm's daily return on $5 \%$ worst return days of the market (S\&P 500 instead of for the firm) during the calendar year; $E S, M E S$ are expressed in percentage terms. Rating is generated by converting the bond ratings to a cardinal scale measured on a 23 point scale for ratings issued by S\&P, Moody's and Fitch and then taking their average for a given firm. The firms are categorized into 4 firm-types: Depositories (2-digit SIC code=60); Broker-Dealers (4-digit SIC code=6211); Insurance (2-digit SIC code=60 \& 64); Other (2-digit SIC code=61, 62(except 6211), 65, 67). Standard bond yield regression controls which are defined in Appendix B and included in the regression specification are: log assets, profitability, long-term debt to assets, leverage, term spread, log issue size, years to maturity. Firm-type fixed effects (FE) are included by defining a dummy variable $d_{-}$Firm-Type for each firm-type that is set to 1 if a firm belongs to that firm-type or else it is set to 0. Bond-type fixed effects are controlled by including d_Agency, d_Sub and d_Callable which are dummy variables set to 1 if the type of bond is an agency debt, subordinated or callable respectively or else they are set to 0 . Year fixed effects are included in the regressions. All standard errors are clustered at firm level to correct for correlation across observations of a given firm. All t-statistics are displayed in brackets. ${ }^{*},{ }^{* *}$ and $* * *$ indicate significance greater than $10 \%$, $5 \%$ and $1 \%$, respectively. 


\begin{tabular}{|c|c|c|c|c|}
\hline \multirow[b]{3}{*}{ Tail Risk Vars } & \multicolumn{2}{|c|}{ All Controls } & \multicolumn{2}{|c|}{ No Firm Controls } \\
\hline & $(1)$ & $(2)$ & $(3)$ & $(4)$ \\
\hline & & & & \\
\hline $\mathrm{ES}$ & $\begin{array}{c}10.25^{* * *} \\
(3.12)\end{array}$ & & $\begin{array}{c}14.80^{* * *} \\
(4.09)\end{array}$ & \\
\hline MES & & $\begin{array}{c}3.47 \\
(1.09)\end{array}$ & & $\begin{array}{c}2.97 \\
(0.84)\end{array}$ \\
\hline \multicolumn{5}{|l|}{ Firm Vars } \\
\hline Market Leverage & $\begin{array}{c}0.63^{* *} \\
(2.42)\end{array}$ & $\begin{array}{c}0.79^{* * *} \\
(2.64)\end{array}$ & & \\
\hline LongTermDebt_Assets & $\begin{array}{c}50.35^{* * *} \\
(2.68)\end{array}$ & $\begin{array}{c}51.26^{* * *} \\
(2.63)\end{array}$ & & \\
\hline Assets (log) & $\begin{array}{c}1.43 \\
(0.44)\end{array}$ & $\begin{array}{c}2.27 \\
(0.68)\end{array}$ & & \\
\hline Profitability & $\begin{array}{c}-2.83 \\
(-0.16)\end{array}$ & $\begin{array}{l}-5.90 \\
(-0.33)\end{array}$ & & \\
\hline \multicolumn{5}{|l|}{ Bond Vars } \\
\hline d_Agency & $\begin{array}{c}-5.85 \\
(-0.34)\end{array}$ & $\begin{array}{c}-3.99 \\
(-0.22)\end{array}$ & $\begin{array}{c}-65.06^{* * *} \\
(-7.59)\end{array}$ & $\begin{array}{c}-69.98^{* * *} \\
(-7.52)\end{array}$ \\
\hline Rating Scale & $\begin{array}{c}12.81^{* * *} \\
(5.10)\end{array}$ & $\begin{array}{c}14.22^{* * *} \\
(5.60)\end{array}$ & & \\
\hline Maturity (yrs) & $\begin{array}{c}1.11^{* * * *} \\
(4.56)\end{array}$ & $\begin{array}{c}1.01^{* * *} \\
(4.04)\end{array}$ & $\begin{array}{c}0.76^{* * *} \\
(2.70)\end{array}$ & $\begin{array}{l}0.55^{*} \\
(1.84)\end{array}$ \\
\hline IssueSize (log) & $\begin{array}{c}-16.31^{* * *} \\
(-3.39)\end{array}$ & $\begin{array}{c}-16.98^{* * *} \\
(-3.56)\end{array}$ & $\begin{array}{c}-22.32^{* * *} \\
(-4.99)\end{array}$ & $\begin{array}{c}-22.96^{* * *} \\
(-4.93)\end{array}$ \\
\hline \multicolumn{5}{|l|}{ Macro Vars } \\
\hline 10yr-1yr Treasury Spread & $\begin{array}{l}-8.48^{*} \\
(-1.68) \\
\end{array}$ & $\begin{array}{c}-5.15 \\
(-1.06) \\
\end{array}$ & $\begin{array}{c}-14.39^{* *} \\
(-2.46) \\
\end{array}$ & $\begin{array}{c}-9.08 \\
(-1.62) \\
\end{array}$ \\
\hline $\mathrm{N}$ & 1873 & 1873 & 1873 & 1873 \\
\hline Adj. $R^{2}$ & 0.577 & 0.569 & 0.536 & 0.518 \\
\hline Year FE & $\checkmark$ & $\checkmark$ & $\checkmark$ & $\checkmark$ \\
\hline FirmType FE & $\checkmark$ & $\checkmark$ & $\checkmark$ & $\checkmark$ \\
\hline BondType FE & $\checkmark$ & $\checkmark$ & $\checkmark$ & $\checkmark$ \\
\hline
\end{tabular}




\section{Table IV: Bond Yield Spreads and Other Risk Measures}

The following table displays the pricing effect of other risk measures, which are closely related to tail risk, on bond yield issuance in the primary market controlling for bond and firm characteristics during the period from 1990 to 2010. Our risk measures are defined as the following: $\mathbf{E S}_{\text {idio }}$ : is the residual plus constant upon regressing $E S$ on $M E S$ separately for each firm-type; SD_abnret: is the standard deviation of daily "excess" return for the firm (i.e., firm's daily return minus daily return on S\&P 500) over the calendar year; Beta: is the estimate of the coefficient upon regressing the firm's daily return on market's daily return (S\&P 500). SD_abnret, MES, ES idio are expressed in percentage terms. Other variables are defined as: Yield Spread is the bond yield minus closest benchmark treasury yield expressed in basis points. The firms are categorized into 4 firm-types: Depositories (2-digit SIC code=60); Broker-Dealers (4-digit SIC code=6211); Insurance (2-digit SIC code=60 \& 64); Other (2-digit SIC code=61, 62(except 6211), 65, 67). d_firm - type is defined as a dummy variable that is set to 1 if a firm belongs to that firm-type or else it is set to 0 . $d_{-}$Agency, $d_{-} S u b$ and $d_{-}$Callable are dummy variables set to 1 if the type of bond is an agency debt, subordinated or callable respectively or else they are set to 0. Standard bond yield regression controls which are defined in Appendix B and included in the regression specification are: log assets, profitability, long-term debt to assets, leverage, term spread, log issue size, years to maturity and rating scale Year fixed effects are included in the regressions. All standard errors are clustered at firm level to correct for correlation across observations of a given firm.

All t-statistics are displayed in brackets. $*, * *$ and $* * *$ indicate significance greater than $10 \%, 5 \%$ and $1 \%$, respectively. 


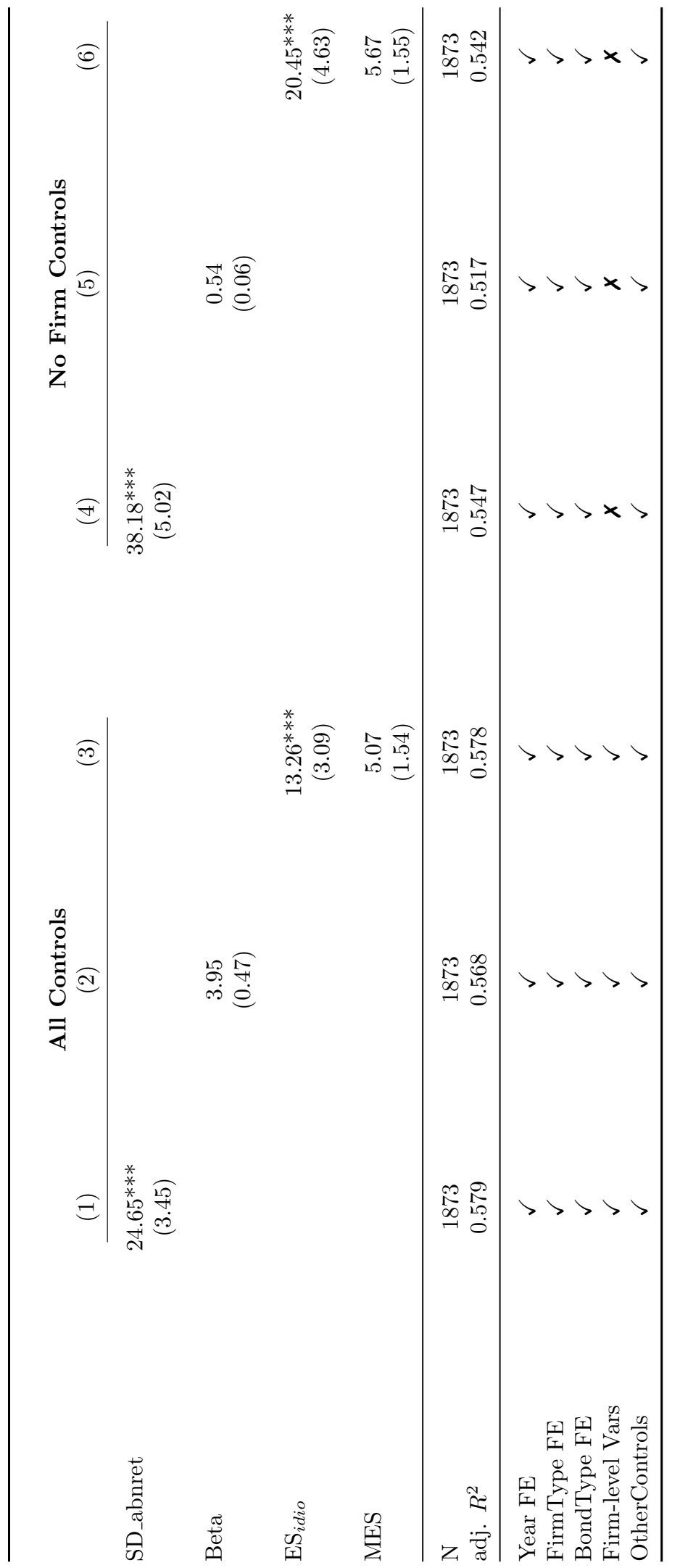




\section{Table V: Bond Characteristics and Pricing of Tail Risk}

The following table displays the primary bond yield regressions with dependent variable as bond yield minus closest benchmark treasury yield expressed in basis points on firm tail-risk measures and other bond characteristics during the period from 1990 to 2010. The analysis consists of the interaction results of tail-risk measures with bond features which are defined in the following manner: Dummy variable $d_{-} S u b$ is set to 1 if the bond is subordinated else it is set to 0 . Dummy variables $d_{-}$LowGrade is set to 1 if it's rating scale $\geq 5$ (A or lower for S\&P, Fitch and Moodys') implying they are medium-grade bonds else it is set 0 implying they are high-grade bonds (AAA or AA - High-grade AAA and AA bonds constitute about $33 \%$ of the sample; Medium grade A to BBB constitute $63 \%$ and the rest $4 \%$ are speculative grade bonds). Similarly $d_{-}$LongMat is set to 1 if the years to maturity of the bond is $\geq 10$ (the mean and median maturity in the sample is close to 10 years) else it is set to 0 . Our tail risk measures are defined as: ES: the negative of the average of the firm's daily returns on $5 \%$ worst return days during the calendar year for the firm; MES: the negative of the average firm's daily return on $5 \%$ worst return days of the market (S\&P 500 instead of for the firm) during the calendar year; $E S, M E S$ are expressed in percentage terms. Rating is generated by converting the bond ratings to a cardinal scale measured on a 23 point scale for ratings issued by S\&P, Moody's and Fitch and then taking their average for a given firm. The firms are categorized into 4 firm-types: Depositories (2-digit SIC code=60); Broker-Dealers (4-digit SIC code=6211); Insurance (2-digit SIC code=60 \& 64); Other (2-digit SIC code=61, 62(except 6211), 65, 67). Standard bond yield regression controls which are defined in Appendix B and included in the regression specification are: log assets, profitability, long-term debt to assets, leverage, term spread, log issue size, years to maturity. Firm-type fixed effects (FE) are included by defining a dummy variable $d_{-}$Firm-Type for each firm-type that is set to 1 if a firm belongs to that firm-type or else it is set to 0 . Bond-type fixed effects are controlled by including dummy variables $d \_$Agency, $d_{-} S u b$ and $d_{-}$Callable. Year fixed effects are included in the regressions. All standard errors are clustered at firm level to correct for correlation

across observations of a given firm. All t-statistics are displayed in brackets. ${ }^{*},{ }^{* *}$ and ${ }^{* * *}$ indicate significance greater than $10 \%, 5 \%$ and $1 \%$, respectively. 


\begin{tabular}{|c|c|c|c|c|c|c|}
\hline \multirow{3}{*}{ ES } & \multirow{2}{*}{\multicolumn{2}{|c|}{$\begin{array}{l}\text { Subordinated } \\
(1)\end{array}$}} & \multicolumn{2}{|c|}{ Low Grade } & \multicolumn{2}{|c|}{ Bond Maturity } \\
\hline & & & (3) & $(4)$ & $(5)$ & $(6)$ \\
\hline & $\begin{array}{l}7.50^{* *} \\
(2.18)\end{array}$ & & $\begin{array}{l}-0.38 \\
(-0.09)\end{array}$ & & $\begin{array}{c}11.36^{* * * *} \\
(2.98)\end{array}$ & \\
\hline MES & & $\begin{array}{c}3.15 \\
(0.96)\end{array}$ & & $\begin{array}{c}-4.34 \\
(-0.92)\end{array}$ & & $\begin{array}{c}3.92 \\
(1.06)\end{array}$ \\
\hline d_Sub $\times$ ES & $\begin{array}{c}11.72^{* *} \\
(2.10)\end{array}$ & & & & & \\
\hline d_Sub $\times$ MES & & $\begin{array}{c}2.27 \\
(0.31)\end{array}$ & & & & \\
\hline d_LowGrade $\times$ ES & & & $\begin{array}{c}18.36^{* * *} \\
(4.72)\end{array}$ & & & \\
\hline d_LowGrade $\times$ MES & & & & $\begin{array}{c}14.65^{* * *} \\
(3.09)\end{array}$ & & \\
\hline $\mathrm{d} \_$LongMat $\times \mathrm{ES}$ & & & & & $\begin{array}{l}-3.63 \\
(-1.08)\end{array}$ & \\
\hline d_LongMat $\times$ MES & & & & & & $\begin{array}{c}-1.13 \\
(-0.31)\end{array}$ \\
\hline d_Sub & $\begin{array}{c}2.42 \\
(0.29)\end{array}$ & $\begin{array}{c}1.61 \\
(0.18)\end{array}$ & $\begin{array}{l}13.85^{*} \\
(1.74)\end{array}$ & $\begin{array}{l}13.38 \\
(1.61)\end{array}$ & $\begin{array}{c}4.32 \\
(0.48)\end{array}$ & $\begin{array}{c}4.66 \\
(0.51)\end{array}$ \\
\hline d LowGrade & & & $\begin{array}{c}5.64 \\
(0.74)\end{array}$ & $\begin{array}{c}2.61 \\
(0.34)\end{array}$ & & \\
\hline d_LongMat & & & & & $\begin{array}{l}8.41^{*} \\
(1.86)\end{array}$ & $\begin{array}{c}6.32 \\
(1.27)\end{array}$ \\
\hline$\Sigma$ Coeff & $\begin{array}{c}19.22^{* * *} \\
(3.37)\end{array}$ & $\begin{array}{c}5.42 \\
(0.74)\end{array}$ & $\begin{array}{c}17.98^{* * *} \\
(5.05)\end{array}$ & $\begin{array}{c}10.31^{* * * *} \\
(2.81)\end{array}$ & $\begin{array}{l}7.73^{* *} \\
(2.34)\end{array}$ & $\begin{array}{l}2.80 \\
(0.79)\end{array}$ \\
\hline $\mathrm{N}$ & 1873 & 1873 & 1873 & 1873 & 1873 & 1873 \\
\hline $\operatorname{adj} \cdot R^{2}$ & 0.580 & 0.569 & 0.563 & 0.542 & 0.574 & 0.565 \\
\hline Year FE & $\checkmark$ & $\checkmark$ & $\checkmark$ & $\checkmark$ & $\checkmark$ & $\checkmark$ \\
\hline FirmType FE & $\checkmark$ & $\checkmark$ & $\checkmark$ & $\checkmark$ & $\checkmark$ & $\checkmark$ \\
\hline BondType FE & $\checkmark$ & $\checkmark$ & $\checkmark$ & $\checkmark$ & $\checkmark$ & $\checkmark$ \\
\hline Rating & $\checkmark$ & $\checkmark$ & $x$ & $x$ & $\checkmark$ & $\checkmark$ \\
\hline Maturity & $\checkmark$ & $\checkmark$ & $\checkmark$ & $\checkmark$ & $x$ & $x$ \\
\hline OtherControls & $\checkmark$ & $\checkmark$ & $\checkmark$ & $\checkmark$ & $\checkmark$ & $\checkmark$ \\
\hline
\end{tabular}




\section{Table VI: Firm Characteristics and Pricing of Tail Risk}

The following table displays the primary bond yield regressions with dependent variable as bond yield minus closest benchmark treasury yield expressed in basis points on firm tail-risk measures and other firm characteristics during the period from 1990 to 2010. The analysis consists of the interaction results of tail-risk measures with firm features which are defined in the following manner: $d_{-}$Large is a dummy variable set to 1 if the $\log$ of firm assets is greater than the median in the universe of financial firms in COMPUSTAT, else it is set to 0 . d_HighLeverage is a dummy variable set to 1 if the firm leverage is greater than the median in the universe of financial firms in COMPUSTAT, else it is set to 0. d_Agency is set to 1 if the bond is an agency bond else it is set to 0. Our tail risk measures are defined as: ES: the negative of the average of the firm's daily returns on $5 \%$ worst return days during the calendar year for the firm; MES: the negative of the average firm's daily return on $5 \%$ worst return days of the market (S\&P 500 instead of for the firm) during the calendar year; $E S, M E S$ are expressed in percentage terms. Rating is generated by converting the bond ratings to a cardinal scale measured on a 23 point scale for ratings issued by S\&P, Moody's and Fitch and then taking their average for a given firm. The firms are categorized into 4 firm-types: Depositories (2-digit SIC code=60); Broker-Dealers (4-digit SIC code=6211); Insurance (2-digit SIC code=60 \& 64); Other (2-digit SIC code=61, 62(except 6211), 65, 67). Standard bond yield regression controls which are defined in Appendix B and included in the regression specification are: log assets, profitability, long-term debt to assets, leverage, term spread, log issue size, years to maturity. Firm-type fixed effects (FE) are included by defining a dummy variable $d \_$Firm-Type for each firm-type that is set to 1 if a firm belongs to that firm-type or else it is set to 0. Bond-type fixed effects are controlled by including dummy variables $d \_$Agency, d_Sub and d_Callable. Year fixed effects are included in the regressions. All standard errors are clustered at firm level to correct for correlation across observations of a given firm. All t-statistics are displayed in brackets. ${ }^{*},{ }^{*}$ and ${ }^{* * *}$ indicate significance greater than $10 \%, 5 \%$ and $1 \%$, respectively. 


\begin{tabular}{|c|c|c|c|c|c|c|}
\hline & & & Lev & & Ager & Debt \\
\hline & (1) & (2) & (3) & (4) & $(5)$ & (6) \\
\hline ES & $\begin{array}{c}17.97^{* * *} \\
(3.33)\end{array}$ & & $\begin{array}{c}10.82^{* *} \\
(2.44)\end{array}$ & & $\begin{array}{c}11.62^{* * *} \\
(3.43)\end{array}$ & \\
\hline MES & & $\begin{array}{l}10.30 \\
(1.51)\end{array}$ & & $\begin{array}{c}2.26 \\
(0.50)\end{array}$ & & $\begin{array}{c}4.99 \\
(1.55)\end{array}$ \\
\hline d_Large*ES & $\begin{array}{c}-10.14^{*} \\
(-1.72)\end{array}$ & & & & & \\
\hline d_Large*MES & & $\begin{array}{c}-5.98 \\
(-0.86)\end{array}$ & & & & \\
\hline d_Leverage*ES & & & $\begin{array}{c}-0.77 \\
(-0.16)\end{array}$ & & & \\
\hline d_Leverage*MES & & & & $\begin{array}{c}0.66 \\
(0.13)\end{array}$ & & \\
\hline d_Agency*ES & & & & & $\begin{array}{c}-29.98^{* * *} \\
(-5.35)\end{array}$ & \\
\hline d_Agency*MES & & & & & & $\begin{array}{c}-32.84^{* * *} \\
(-4.40)\end{array}$ \\
\hline d_Large & $\begin{array}{l}-16.45 \\
(-1.58)\end{array}$ & $\begin{array}{l}-18.26 \\
(-1.49)\end{array}$ & & & & \\
\hline d_Leverage & & & $\begin{array}{l}13.43 \\
(1.33)\end{array}$ & $\begin{array}{l}19.31^{*} \\
(1.90)\end{array}$ & & \\
\hline d_Agency & $\begin{array}{c}-3.03 \\
(-0.18)\end{array}$ & $\begin{array}{l}-1.15 \\
(-0.07)\end{array}$ & $\begin{array}{l}12.35 \\
(0.78)\end{array}$ & $\begin{array}{l}14.57 \\
(0.90)\end{array}$ & $\begin{array}{l}-12.98 \\
(-0.74)\end{array}$ & $\begin{array}{c}-5.67 \\
(-0.31)\end{array}$ \\
\hline$\Sigma$ Coeff & $\begin{array}{l}7.83^{* *} \\
(2.31)\end{array}$ & $\begin{array}{c}4.32 \\
(1.32)\end{array}$ & $\begin{array}{c}10.05^{* * * *} \\
(2.74)\end{array}$ & $\begin{array}{c}2.92 \\
(0.79)\end{array}$ & $\begin{array}{c}-18.36^{* * *} \\
(-3.37)\end{array}$ & $\begin{array}{c}-27.85^{* * *} \\
(-3.95)\end{array}$ \\
\hline $\begin{array}{l}\mathrm{N} \\
\text { adj. } R^{2}\end{array}$ & $\begin{array}{c}1873 \\
0.581\end{array}$ & $\begin{array}{c}1873 \\
0.570\end{array}$ & $\begin{array}{c}1873 \\
0.573\end{array}$ & $\begin{array}{c}1873 \\
0.565\end{array}$ & $\begin{array}{c}1873 \\
0.581\end{array}$ & $\begin{array}{l}1873 \\
0.571\end{array}$ \\
\hline Year FE & $\checkmark$ & $\checkmark$ & $\checkmark$ & $\checkmark$ & $\checkmark$ & $\checkmark$ \\
\hline FirmType FE & $\checkmark$ & $\checkmark$ & $\checkmark$ & $\checkmark$ & $\checkmark$ & $\checkmark$ \\
\hline BondType FE & $\checkmark$ & $\checkmark$ & $\checkmark$ & $\checkmark$ & $\checkmark$ & $\checkmark$ \\
\hline LogAssets & $x$ & $x$ & $\checkmark$ & $\checkmark$ & $\checkmark$ & $\checkmark$ \\
\hline Leverage & $\checkmark$ & $\checkmark$ & $x$ & $x$ & $\checkmark$ & $\checkmark$ \\
\hline RatingScale & $\checkmark$ & $\checkmark$ & $\checkmark$ & $\checkmark$ & $\checkmark$ & $\checkmark$ \\
\hline OtherControls & $\checkmark$ & $\checkmark$ & $\checkmark$ & $\checkmark$ & $\checkmark$ & $\checkmark$ \\
\hline
\end{tabular}




\section{Table VII: Pricing of Tail Risk for Different Institution Types}

The following table displays the primary bond yield regressions with dependent variable as bond yield minus closest benchmark treasury yield expressed in basis points on firm tail-risk measures and other firm and bond characteristics during the period from 1990 to 2010 separately for each firm type. Our tail risk measures are defined as: ES: the negative of the average of the firm's daily returns on $5 \%$ worst return days during the calendar year for the firm; MES: the negative of the average firm's daily return on $5 \%$ worst return days of the market (S\&P 500 instead of for the firm) during the calendar year; ES, MES are expressed in percentage terms. Rating is generated by converting the bond ratings to a cardinal scale measured on a 23 point scale for ratings issued by S\&P, Moody's and Fitch and then taking their average for a given firm. The firms are categorized into 4 firm-types: Depositories (2-digit SIC code=60); Broker-Dealers (4-digit SIC code=6211); Insurance (2-digit SIC code=60 \& 64); Other (2-digit SIC code=61, 62(except 6211), 65, 67). Standard bond yield regression controls which are defined in Appendix B and included in the regression specification are: log assets, profitability, long-term debt to assets, leverage, term spread, log issue size, years to maturity. Firm-type fixed effects (FE) are included by defining a dummy variable $d_{-}$Firm-Type for each firm-type that is set to 1 if a firm belongs to that firm-type or else it is set to 0. Bond-type fixed effects are controlled by including $d_{-}$Agency, $d_{-} S u b$ and $d \_C a l l a b l e$ which are dummy variables set to 1 if the type of bond is an agency debt, subordinated or callable respectively or else they are set to 0. Year fixed effects are included in the regressions. All standard errors are clustered at firm level to correct for correlation across observations of a given firm. All t-statistics are displayed in brackets. *, ** and *** indicate significance greater than $10 \%, 5 \%$ and $1 \%$, respectively.

Panel A analyzes the effect of tail-risk on bond issuance yields controlling for all our bond-level, firm-level and macroeconomic variables. Panel B analyzes the incremental effect of tail-risk on subordinated bond issuance yields controlling for all our bond-level, firm-level and macroeconomic variables. 


\section{Panel A: Only Tail Risk}

\section{Depository}

(1)

(2)

ES

$$
-1.45
$$

$(-0.22)$

\section{Broker-Dealer}

(3) (4)

$37.92^{* * *}$

(3.34)
Insurance

(5)

$11.85^{*}$

(1.68)
Other

(7)

(8)

$15.56^{* * *}$

(3.57)

\begin{tabular}{|c|c|c|c|c|c|c|c|c|}
\hline MES & & $\begin{array}{l}-8.57 \\
(-0.98)\end{array}$ & & $\begin{array}{c}35.68^{* * *} \\
(3.59)\end{array}$ & & $\begin{array}{c}16.28^{* *} \\
(2.44)\end{array}$ & & $\begin{array}{c}5.23 \\
(1.10)\end{array}$ \\
\hline $\begin{array}{l}\mathrm{N} \\
\text { adj. } R^{2}\end{array}$ & $\begin{array}{c}470 \\
0.476\end{array}$ & $\begin{array}{c}470 \\
0.478\end{array}$ & $\begin{array}{c}228 \\
0.494\end{array}$ & $\begin{array}{c}228 \\
0.483\end{array}$ & $\begin{array}{c}269 \\
0.552\end{array}$ & $\begin{array}{c}269 \\
0.558\end{array}$ & $\begin{array}{c}906 \\
0.656\end{array}$ & $\begin{array}{c}906 \\
0.635\end{array}$ \\
\hline Year FE & $\checkmark$ & $\checkmark$ & $\checkmark$ & $\checkmark$ & $\checkmark$ & $\checkmark$ & $\checkmark$ & $\checkmark$ \\
\hline BondType FE & $\checkmark$ & $\checkmark$ & $\checkmark$ & $\checkmark$ & $\checkmark$ & $\checkmark$ & $\checkmark$ & $\checkmark$ \\
\hline OtherControls & $\checkmark$ & $\checkmark$ & $\checkmark$ & $\checkmark$ & $\checkmark$ & $\checkmark$ & $\checkmark$ & $\checkmark$ \\
\hline
\end{tabular}

Panel B: Tail Risk $\times$ Subordinated

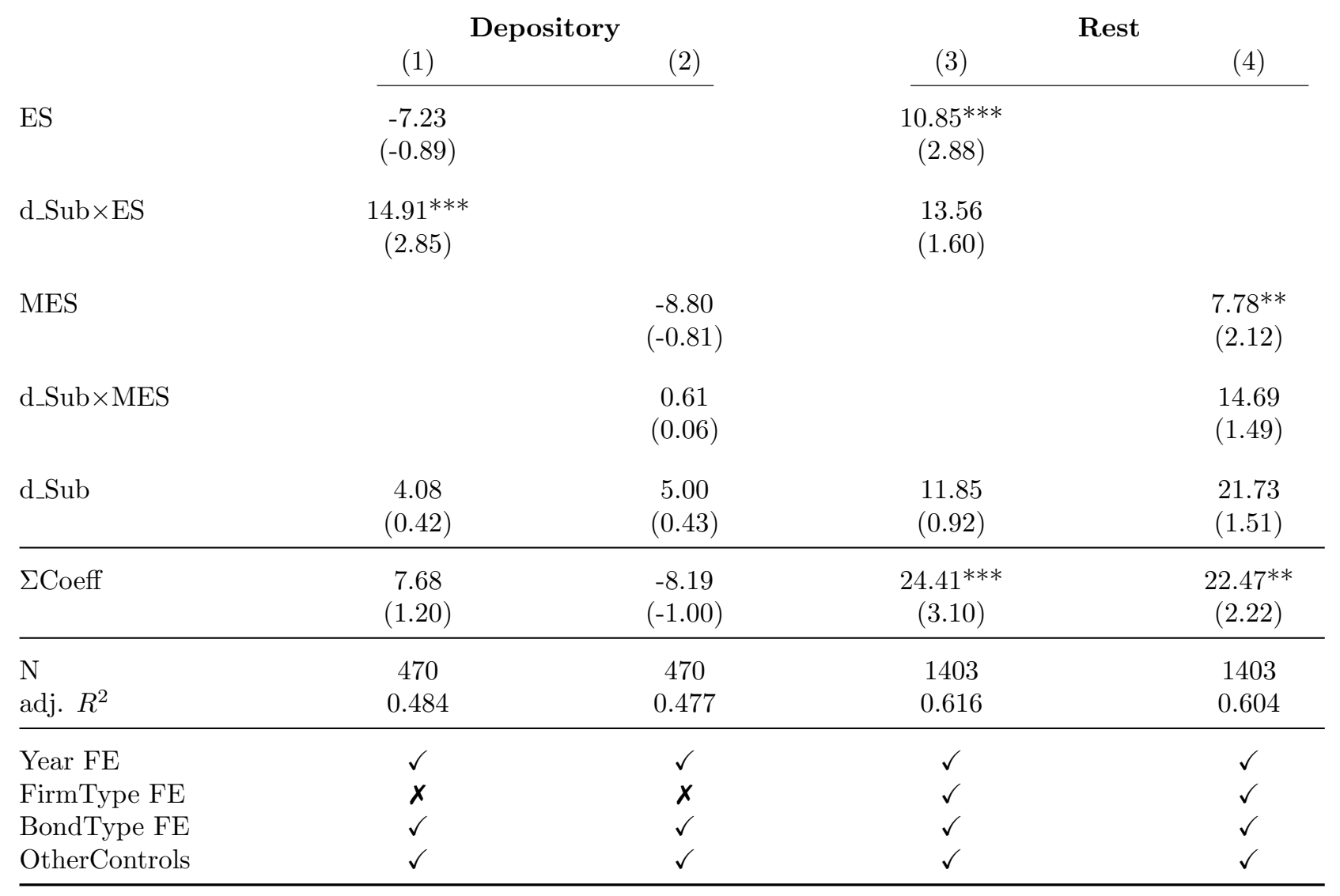




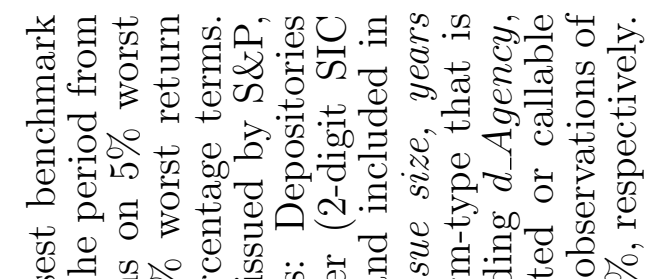

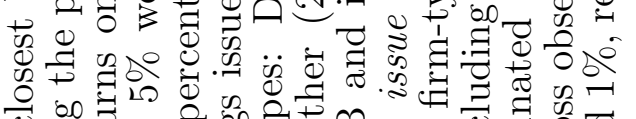

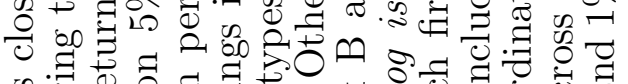

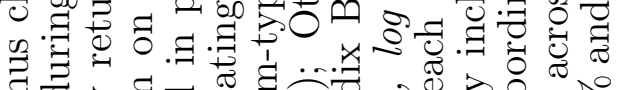

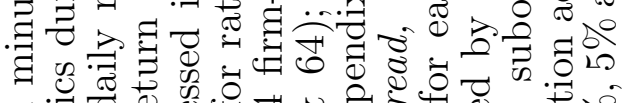

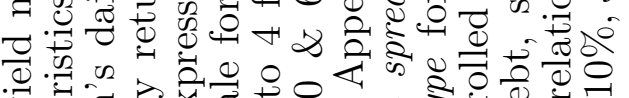
을. 5

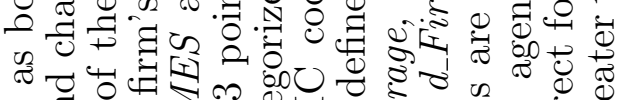

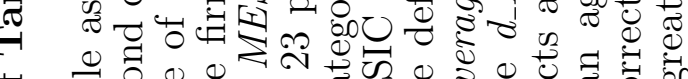

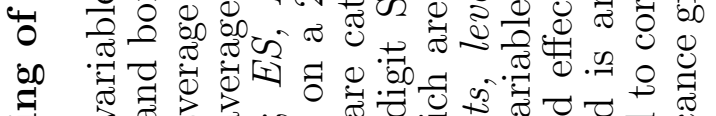

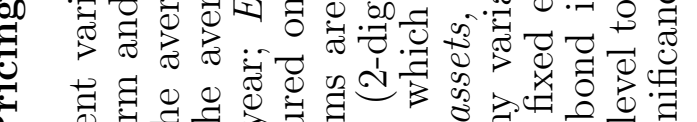

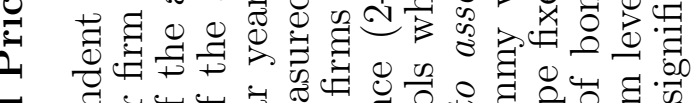

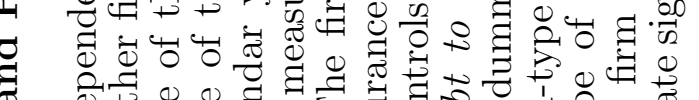

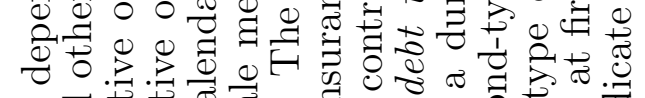

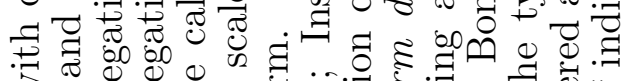

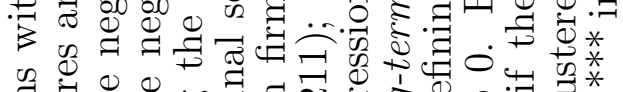

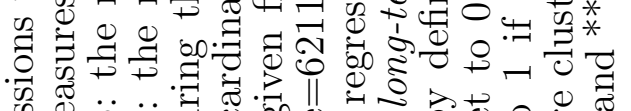

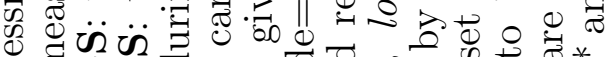

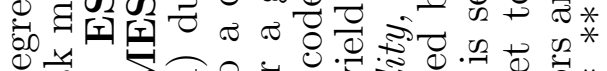

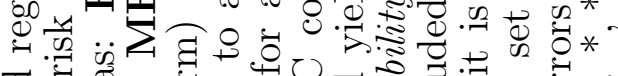

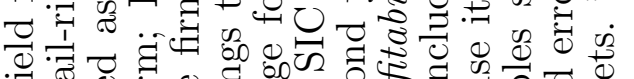

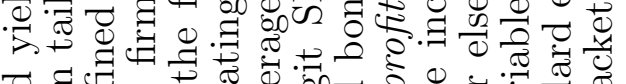

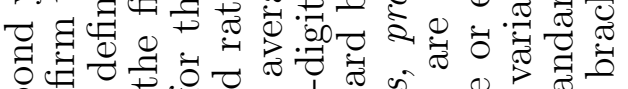

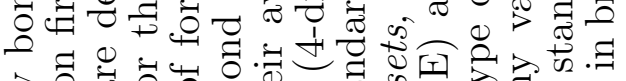

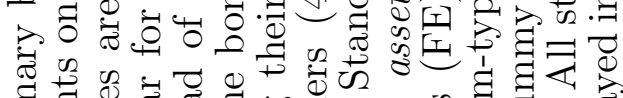

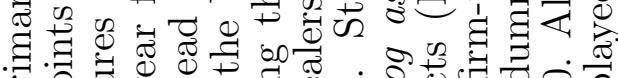

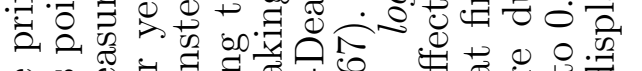

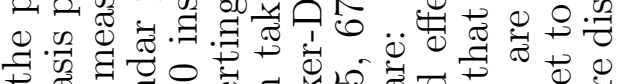

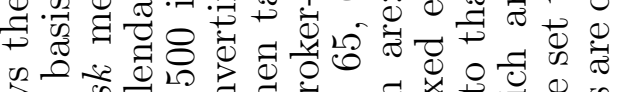

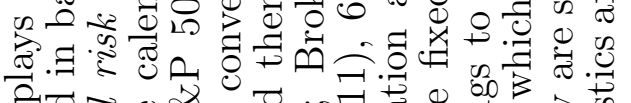

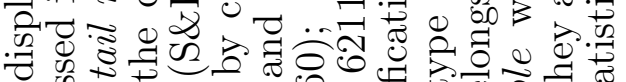

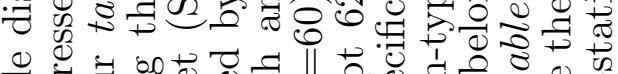

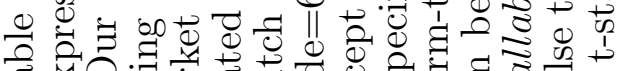

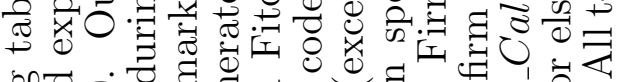

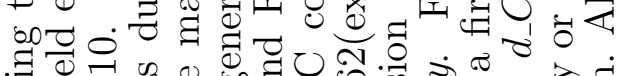

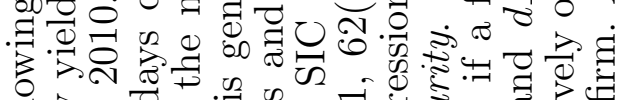

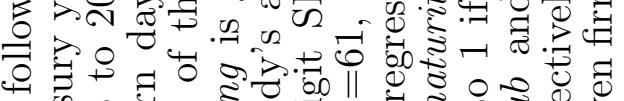

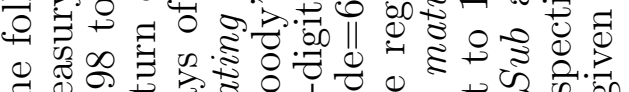

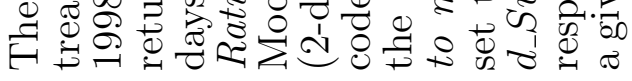

.

ค.

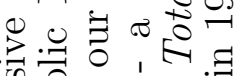

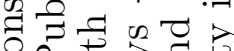

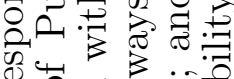

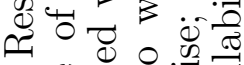

- 00

울

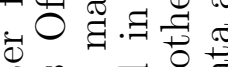

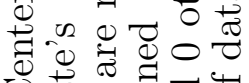

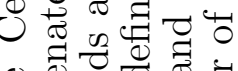

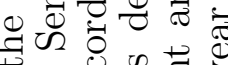

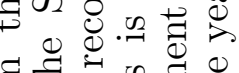

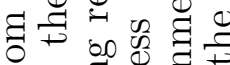

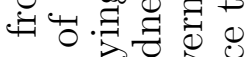
㐘 跑. $\exists$ 过 "ᄏ

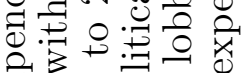

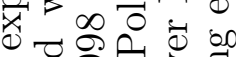

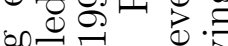
च घ घं वै

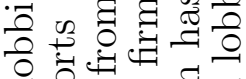
0

$=0$ 西藏

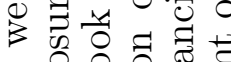
क 设

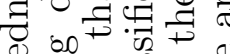

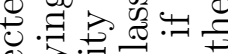
든

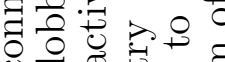
U- 00 药

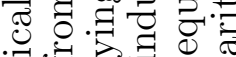
西定.

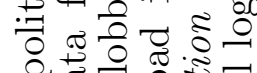
फ บ 范

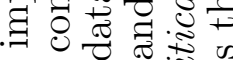
엉 웡 가웡

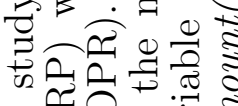

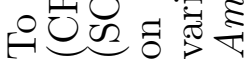




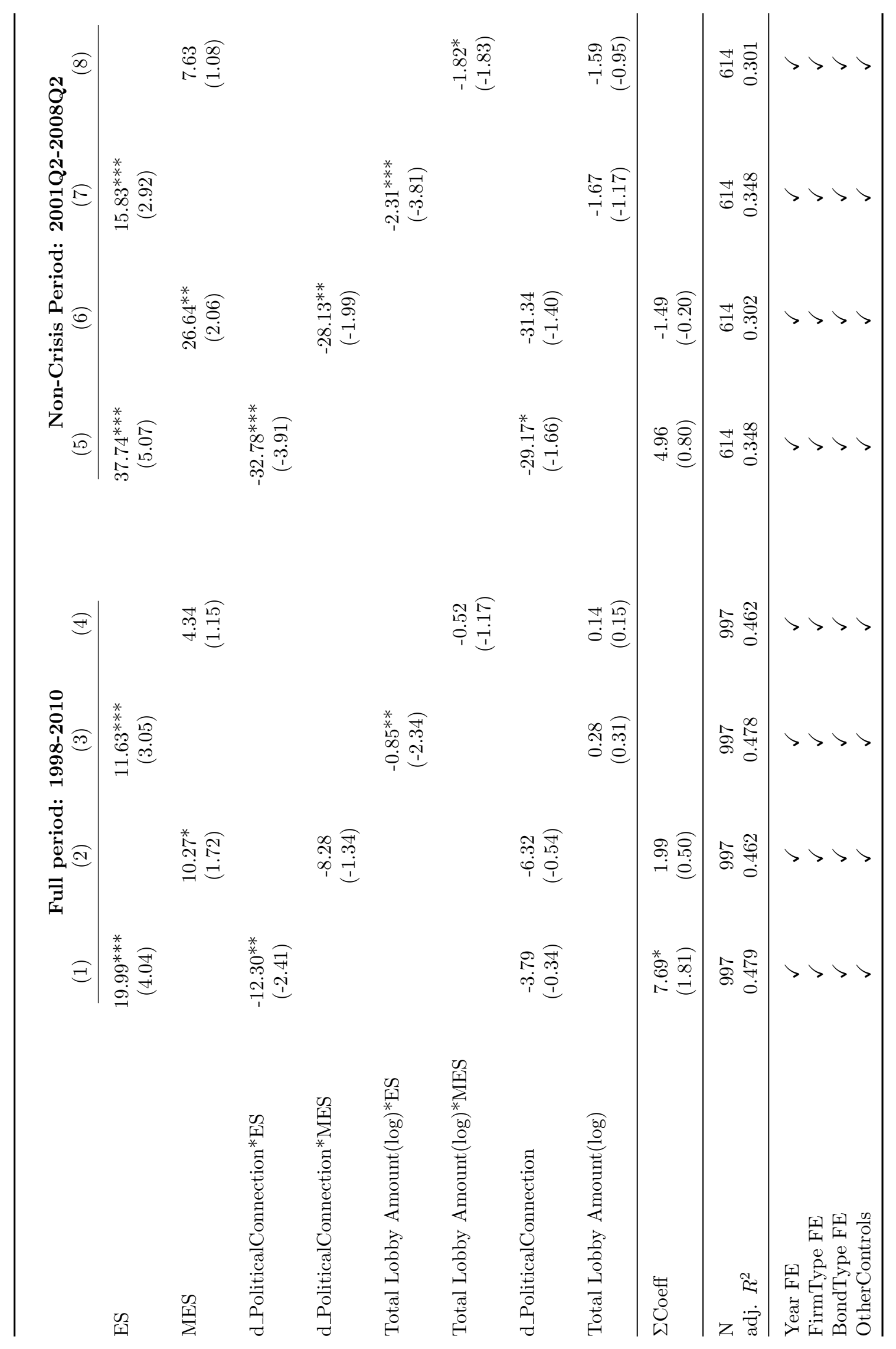




\section{Table IX: Pricing of Tail Risk Around Crisis Periods}

The following table displays the primary bond yield regressions with dependent variable as bond yield minus closest benchmark treasury yield expressed in basis points on firm tail-risk measures and other firm and bond characteristics during the crisis periods from 1990 to 2010. Our tail risk measures are defined as: ES: the negative of the average of the firm's daily returns on 5\% worst return days during the calendar year for the firm; MES: the negative of the average firm's daily return on 5\% worst return days of the market (S\&P 500 instead of for the firm) during the calendar year; ES, MES are expressed in percentage terms. Rating is generated by converting the bond ratings to a cardinal scale measured on a 23 point scale for ratings issued by S\&P, Moody's and Fitch and then taking their average for a given firm. The firms are categorized into 4 firm-types: Depositories (2-digit SIC code=60); Broker-Dealers (4-digit SIC code=6211); Insurance (2-digit SIC code=60 \& 64); Other (2-digit SIC code=61, 62(except 6211), 65, 67). Standard bond yield regression controls which are defined in Appendix B and included in the regression specification are: log assets, profitability, long-term debt to assets, leverage, term spread, log issue size, years to maturity. Firm-type fixed effects (FE) are included by defining a dummy variable d_Firm-Type for each firm-type that is set to 1 if a firm belongs to that firm-type or else it is set to 0 . Bond-type fixed effects are controlled by including $d_{-}$Agency, $d_{-} S u b$ and $d_{-}$Callable which are dummy variables set to 1 if the type of bond is an agency debt, subordinated or callable respectively or else they are set to 0 . All standard errors are clustered at firm level to correct for correlation across observations of a given firm. All t-statistics are displayed in brackets. $*, * *$ and $* * *$ indicate significance greater than $10 \%, 5 \%$ and $1 \%$, respectively.

To study the impact of crisis periods, we construct bond issuance samples of all the financial firms in a 2-year window around the crisis-period and divide the period into equal pre- and post- crisis periods of four quarters each. Post-crisis dummies are defined in the following manner: For bonds issued between the period 1997:Q4 and 1999:Q3, d_LTCM takes the value 1 for all bonds issued between the 1998:Q4 and 1999:Q3, and 0 otherwise. For bonds issued between the period 1999:Q2 and 2001:Q1, d_Dotcom takes the value 1 for all bonds issued between 2000:Q2 and 2001:Q1, and 0 otherwise. For bonds issued between the period 2007:Q4 and 2009:Q3, d_FinCrisis takes the value 1 for all bonds issued between 2008:4Q and 2009:Q3, and 0 otherwise. 


\begin{tabular}{|c|c|c|c|c|c|c|}
\hline \multirow{3}{*}{$\begin{array}{l} \\
\mathrm{ES}\end{array}$} & \multicolumn{2}{|c|}{ LTCM } & \multicolumn{2}{|c|}{ Dotcom } & \multicolumn{2}{|c|}{ Financial Crisis } \\
\hline & (1) & (2) & (3) & (4) & $(5)$ & (6) \\
\hline & $\begin{array}{c}27.57^{* *} \\
(2.09)\end{array}$ & & $\begin{array}{c}2.24 \\
(0.31)\end{array}$ & & $\begin{array}{c}43.41^{* * *} \\
(3.53)\end{array}$ & \\
\hline MES & & $\begin{array}{c}9.57 \\
(1.10)\end{array}$ & & $\begin{array}{l}-7.04 \\
(-1.10)\end{array}$ & & $\begin{array}{l}18.76 \\
(1.09)\end{array}$ \\
\hline d_LTCM $\times E S$ & $\begin{array}{c}-33.16^{* * *} \\
(-2.92)\end{array}$ & & & & & \\
\hline d_LTCM $\times$ MES & & $\begin{array}{c}-16.55^{* *} \\
(-2.03)\end{array}$ & & & & \\
\hline d_DotCom $\times$ ES & & & $\begin{array}{c}9.65 \\
(1.24)\end{array}$ & & & \\
\hline d_DotCom $\times$ MES & & & & $\begin{array}{l}-17.10 \\
(-1.36)\end{array}$ & & \\
\hline $\mathrm{d} \_$FinCrisis $\times$ES & & & & & $\begin{array}{c}-61.22^{* *} \\
(-2.51)\end{array}$ & \\
\hline d_FinCrisis $\times$ MES & & & & & & $\begin{array}{c}-74.70^{* * *} \\
(-3.41)\end{array}$ \\
\hline d_LTCM & $\begin{array}{c}70.28^{* * *} \\
(2.77)\end{array}$ & $\begin{array}{c}86.66^{* * *} \\
(4.08)\end{array}$ & & & & \\
\hline d_DotCom & & & $\begin{array}{c}47.77^{* * *} \\
(3.81)\end{array}$ & $\begin{array}{c}40.31^{* * *} \\
(2.80)\end{array}$ & & \\
\hline d_FinCrisis & & & & & $\begin{array}{c}175.59^{* * *} \\
(2.80)\end{array}$ & $\begin{array}{c}230.37^{* * *} \\
(5.11)\end{array}$ \\
\hline$\Sigma$ Coeff & $\begin{array}{l}-5.59 \\
(-0.88)\end{array}$ & $\begin{array}{l}-6.98 \\
(-1.25)\end{array}$ & $\begin{array}{l}11.89 \\
(1.17)\end{array}$ & $\begin{array}{c}-24.13^{*} \\
(-1.69)\end{array}$ & $\begin{array}{l}-17.82 \\
(-0.71)\end{array}$ & $\begin{array}{c}-55.95^{* * *} \\
(-2.86)\end{array}$ \\
\hline $\begin{array}{l}\mathrm{N} \\
\text { adj. } R^{2}\end{array}$ & $\begin{array}{c}154 \\
0.656\end{array}$ & $\begin{array}{c}154 \\
0.602\end{array}$ & $\begin{array}{c}126 \\
0.364\end{array}$ & $\begin{array}{c}126 \\
0.374\end{array}$ & $\begin{array}{c}100 \\
0.605\end{array}$ & $\begin{array}{c}100 \\
0.626\end{array}$ \\
\hline Year FE & $x$ & $x$ & $x$ & $x$ & $x$ & $x$ \\
\hline FirmType FE & $\checkmark$ & $\checkmark$ & $\checkmark$ & $\checkmark$ & $\checkmark$ & $\checkmark$ \\
\hline BondType FE & $\checkmark$ & $\checkmark$ & $\checkmark$ & $\checkmark$ & $\checkmark$ & $\checkmark$ \\
\hline OtherControls & $\checkmark$ & $\checkmark$ & $\checkmark$ & $\checkmark$ & $\checkmark$ & $\checkmark$ \\
\hline
\end{tabular}




\section{Table X: Credit Ratings and Tail Risk}

The following table displays the ordered probit regressions with dependent variable as rating scale on tail risk and other firm characteristics during the period from 1990 to 2010 separately for each firm-type. Credit ratings are converted into a cardinal scale starting with 1 as $\mathrm{AAA}(\mathrm{Aaa}), 2$ as $\mathrm{AA}+(\mathrm{Aa} 1), 3$ as $\mathrm{AA}(\mathrm{Aa} 2)$, and so on. Our tail risk measures are defined as: ES: the negative of the average of the firm's daily returns on $5 \%$ worst return days during the calendar year for the firm; MES: the negative of the average firm's daily return on $5 \%$ worst return days of the market (S\&P 500 instead of for the firm) during the calendar year; ES, MES are expressed in percentage terms. The firms are categorized into 4 firm-types: Depositories (2-digit SIC code=60); Broker-Dealers (4-digit SIC code=6211); Insurance (2-digit SIC code=60 \& 64); Other (2-digit SIC code=61, 62(except 6211), 65, 67). Standard bond yield regression controls which are defined in Appendix B and included in the regression specification are: log assets, profitability, long-term debt to assets, leverage, term spread, log issue size, years to maturity. Firm-type fixed effects (FE) are included by defining a dummy variable $d_{-}$Firm-Type for each firm-type that is set to 1 if a firm belongs to that firm-type or else it is set to 0. Bond-type fixed effects are controlled by including $d_{-}$Agency, $d_{-} S u b$ and $d_{-} C$ Callable which are dummy variables set to 1 if the type of bond is an agency debt, subordinated or callable respectively or else they are set to 0. Year fixed effects are included in the regressions. All standard errors are clustered at firm level to correct for correlation across observations of a given firm. All t-statistics are displayed in brackets. ${ }^{*},{ }^{* *}$ and $* * *$ indicate significance greater than $10 \%, 5 \%$ and $1 \%$, respectively.

Panel A analyzes the effect of tail-risk on bond rating assignment by credit rating agencies controlling for all our bond-level, firm-level and macroeconomic variables. Panel B analyzes the incremental effect of tail-risk on subordinated bond rating assignment controlling for all our bond-level, firm-level and macroeconomic variables. 


\section{Panel A: Only Tail Risk}

\begin{tabular}{|c|c|c|c|c|c|c|c|c|}
\hline & \multicolumn{2}{|c|}{ Depository } & \multicolumn{2}{|c|}{ Broker-Dealer } & \multicolumn{2}{|c|}{ Insurance } & \multicolumn{2}{|c|}{ Other } \\
\hline & $(1)$ & $(2)$ & (3) & $(4)$ & $(5)$ & $(6)$ & (7) & (8) \\
\hline ES & $\begin{array}{c}0.27^{* * *} \\
(3.68)\end{array}$ & & $\begin{array}{c}0.08 \\
(0.37)\end{array}$ & & $\begin{array}{c}0.43^{* * *} \\
(4.19)\end{array}$ & & $\begin{array}{c}0.15^{* * *} \\
(2.93)\end{array}$ & \\
\hline MES & & $\begin{array}{c}0.21 \\
(1.46)\end{array}$ & & $\begin{array}{l}-0.30 \\
(-1.17)\end{array}$ & & $\begin{array}{c}0.38^{* * *} \\
(3.31)\end{array}$ & & $\begin{array}{c}0.16^{* *} \\
(2.34)\end{array}$ \\
\hline $\mathrm{N}$ & 470 & 470 & 228 & 228 & 269 & 269 & 906 & 906 \\
\hline Pseudo- $R^{2}$ & 0.298 & 0.290 & 0.368 & 0.375 & 0.189 & 0.175 & 0.436 & 0.433 \\
\hline Year FE & $\checkmark$ & $\checkmark$ & $\checkmark$ & $\checkmark$ & $\checkmark$ & $\checkmark$ & $\checkmark$ & $\checkmark$ \\
\hline BondType FE & $\checkmark$ & $\checkmark$ & $\checkmark$ & $\checkmark$ & $\checkmark$ & $\checkmark$ & $\checkmark$ & $\checkmark$ \\
\hline OtherControls & $\checkmark$ & $\checkmark$ & $\checkmark$ & $\checkmark$ & $\checkmark$ & $\checkmark$ & $\checkmark$ & $\checkmark$ \\
\hline
\end{tabular}

Panel B: Tail Risk $\times$ Subordinated

(1) Depository

ES

d_Sub $\times$ ES

MES

d_Sub $\times$ MES

d_Sub

(7.89)

$\Sigma$ Coeff

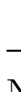

$\mathrm{N}$

Pseudo- $R^{2}$

Year FE

FirmType FE

BondType FE

FirmControls
$0.33^{* * *}$

(3.77)

$-0.17^{*}$

$(-1.79)$

Rest

(3)

$0.18^{* * *}$

(3.92)

$-0.14$

$(-1.36)$

(4)

$\begin{array}{lccc} & 0.17 & & 0.11^{*} \\ & (1.12) & & (1.67) \\ & 0.09 & & 0.09 \\ & (0.78) & & (0.78) \\ & 1.05^{* * *} & & 0.39^{* *} \\ 10^{* * *} & (8.18) & (1.49) & (1.98) \\ 7.89) & 0.26^{*} & 0.04 & 0.20 \\ 0.16^{*} & (1.82) & (0.37) & (1.54) \\ 1.94) & 470 & 1403 & 1403 \\ 470 & 0.290 & 0.376 & 0.371 \\ 0.301 & \checkmark & \checkmark & \checkmark \\ \checkmark & \boldsymbol{x} & \checkmark & \checkmark \\ \boldsymbol{x} & \checkmark & \checkmark & \checkmark \\ \checkmark & \checkmark & \checkmark & \\ \checkmark & & & \end{array}$

